\title{
A New Approach to Reduce the Carbon Footprint in Resistance Spot Welding by Energy Efficiency Evaluation.
}

Carla Ferreira Andrade Cunha ( $\square$ carlaandradecunha@gmail.com )

Instituto Tecnologico de Aeronautica https://orcid.org/0000-0002-2557-9798

Jefferson de Oliveira Gomes

Instituto Tecnologico de Aeronautica

Hugo Marcelo Bezerra de Carvalho

Instituto Tecnologico de Aeronautica

\section{Research Article}

Keywords: Resistance Spot Welding, RSW, Energy Consumption, Efficiency, Parameter optimization

Posted Date: August 7th, 2021

DOI: https://doi.org/10.21203/rs.3.rs-762169/v1

License: (c) (i) This work is licensed under a Creative Commons Attribution 4.0 International License.

Read Full License

Version of Record: A version of this preprint was published at The International Journal of Advanced Manufacturing Technology on January 21st, 2022. See the published version at https://doi.org/10.1007/s00170-021-08472-7. 
Title: A new approach to reduce the carbon footprint in Resistance Spot Welding by energy efficiency evaluation.

\title{
Author information:
}

Carla Ferreira Andrade Cunha ${ }^{\mathrm{a}}$ (https://orcid.org/0000-0002-2557-9798),

Jefferson de Oliveira Gomes ${ }^{\mathrm{a}}$ (https://orcid.org/0000-0002-6004-799X),

Hugo Marcelo Bezerra de Carvalho ${ }^{\mathrm{a}, \mathrm{b}}$ (https://orcid.org/0000-0001-8147-8572),

a Technological Institute of Aeronautics, Praça Marechal Eduardo Gomes, 50 - Vila das Acácias, São José dos Campos, 12.228-970, Brazil

${ }^{\mathrm{b}}$ Renault of Brazil, Av. Renault, 1300, São Jose dos Pinhais, 83070-970, Brazil

\section{Corresponding author:}

Carla Ferreira Andrade Cunha - Tel.: +55-349-9223-5165 - E-mail address: carla@ita.br

\begin{abstract}
:
Actions aiming to reduce energy consumption directly contribute to the reduction of manufacturing costs and carbon footprint while supporting manufacturing processes' productivity. Resistance spot welding is relevant in the automotive sector. Due to its operational characteristics, this process has high energy consumption. Despite this fact, few studies have found to guide solutions for its reduction. In this sense, this study proposes a method to improve the resistance spot welding process's energy performance without compromising its quality. This study applies statistical analysis (ANOVA) to support predictive models that characterize energy and quality performance. The statistical analyses confirmed and quantified the influence of the control factors in energy and quality performance indicators. The predictive models made it possible to anticipate energy consumption and quality behaviour from adjustments in the welding line process parameters studied in this paper. To fit the best compromise between energy consumption and quality, energy labels to classify the process's energy performance were proposed. The best compromise solution for the studied process parameter ranges in this work was: $C_{w e l}: 8 \mathrm{kA}, T_{w e l}: 8$ cycles and $F_{\text {ele }}: 343 \mathrm{kgf}$. This parameter combination results in a consumption of approximately $2 \mathrm{Wh}$ per spot weld. Approximately $33 \%$ less than the average estimated consumption per spot weld in the automotive industry.
\end{abstract}

Keywords: Resistance Spot Welding; RSW; Energy Consumption; Efficiency; Parameter optimization 


\section{A new approach to reduce the carbon footprint in Resistance Spot Welding by energy efficiency evaluation.}

\section{Introduction}

Carbon footprints left by manufacturing industries increase as their consumption of electricity boosts [1]. The continuous increase in energy consumption on a global scale, coupled with the rise in its cost pointed out by the International Energy Agency (IEA) [2] and the strengthening of public opinion inflate the industry's concern to reduce the impacts of its manufacturing processes [3]. In addition, Introna et al. [4] indicated that a large number of companies prioritize isolated attempts to reduce their energy consumption through specific projects instead of applying a systemic approach, such a management system described in the norm Energy Management Systems ISO standard 50001:2011 [5].

Daudt and Willcox [6] peak that the automotive industry stands out in the world panorama. It is responsible for the annual manufacture of more than 90 million cars in the last five years. Brazil is the 8th largest producer [7]. As a result, in 2018 alone, 2.88 million motor vehicles were manufactured, using $3.8 \%$ of Brazil's electricity consumption this year [8].

Resistance Spot Welding (RSW) highlights among large amount of manufacturing and assembly processes present in the automotive sector. It is a widely used method for joining two or more overlapping metal sheets by applying a high electric current through electrodes. More than $90 \%$ of the body shop's assembly is carried out by this process [9]. RSW is also frequently applied to transportation vessels, building applications, office items, and kitchen furniture [10].

In a passenger vehicle is between 4,000 to 6,000 welding spots [11]. Therefore, it estimates that the number of spot-welding manufactured globally in 2019 was about 450 trillion [7]. This large volume of production and the high electrical currents applied in the process justifies the interest to investigate RSW energy consumption. Energy analysis, however, must be done without detriment to quality, mainly due to the critical nature of the operation.

Weld spot quality can be assessed using destructive and non-destructive methods. The first is more widespread than the second in the industry. However, due to its 
application, it requires more time than the welding process and cannot be applied to parts to reach consumers. Thus, they are usually carried out by sampling [12].

Since the inspection of the resistance spot welding process is limited by sample, the addition of $30 \%$ of redundant welds and operational parameters combinations that result in a higher thermal input are expected, resulting in a significant waste of energy. However, most previous works as [13], [14], [11], and [15] aim to identify and optimize the quality resulting from the weld spot only from a structural perspective. In the last decade, only $1 \%$ of the total number of publications about resistance spot welding addressed some aspect of the RSW's energy performance. Moreover, no one proposes a method based on empirical experiments to optimize energy consumption and quality simultaneously.

Therefore, this paper aims to present a methodology for improving the RSW's energy performance without compromising its quality. To do so, the paper is structured as follows. In Section 1, the introduction and context of this paper are presented. Section 2 explores previous research on energy evaluation in resistance spot welding. In section 3 , the general methodology is shown, whereas the application of this methodology is shown in section 4. A summary and outlook are given in the last section of this paper, which also shows further research possibilities.

\section{Energy evaluation in resistance spot welding}

The amount of heat released in the spot-welding process will depend on the current applied, the time it passes, and the total resistance of the system. Williams and Parker [11] concluded that the total resistance will depend on the electrical and mechanical nature of the machine, the material and dimensions of the electrodes, the force applied, the number of interfaces, and the material and thickness of the steel sheets being welded. As the temperature increases, the metals in the plates undergo a phase change. Therefore, there is a change in the total resistance of the system. The variation in electrical resistance is described by its time series, called dynamic resistance $\left(R_{\text {din }}\right) . R_{\text {din }}$ is considered a unique parameter, as it can reflect the characteristics of the welded joint in real time.

Process parameters, which can be controlled on a resistance-welding machine, can reflect directly on the dynamic resistance and, consequently, on the quality and energy 
consumption of the process. Therefore, it is possible to determine working ranges to reach an operating window for the welding process in terms of quality. Williams and Parker [11] denominate this interval of the weldability lobe. It is usually defined and confirmed using empirical experiments.

The lower limit of the weldability lobe is defined quantitatively by measuring the weld nugget diameter according to Equation 1, where $t$ is the thinnest sheet thickness, commonly obtained in an industrial environment by the Peel test procedure. Its acquisition, measurement, and analysis are supported by international standards such as ISO 10447 [16].

$$
d_{\text {minimum }}=5 \sqrt{t}
$$

The expulsion identification, which defines the upper limit, is usually carried out in an industrial environment by observation, as shown in Figure 1. It is a recurring phenomenon since it is a frequent practice to use excessive parameters to avoid the production of welds that present interfacial failure mode [17].

[Insert Figure 1 near here]

Fan et al. pointed out that expulsion is directed linked to the quality and energy consumption of the RSW process, and it can be prevented by selecting the correct process parameters. However, the acceptable weld region is just below the expulsion region. Based on that, Podržaj et al. [19] suggested that an efficient and reliable expulsion detection is required.

Studies were found to detect expulsion using diversified input data. Farson et al. [20] studied three input data variables: voltage, electrode displacement, and force change. In addition, Bhole et al. [21] and Fan et al. [17] studied the dynamic resistance's influence. Other studies analysed electrode displacement [22], electrode force [23], and acoustics signals [24].

In the study developed by Podržaj et al. [19], in turn, different signals were tested as data input to an LVQ (Learning Vector Quantization) network to identify the best combination for detecting the expulsion. The signs of dynamic resistance, electrode displacement, and force were monitored. In this study, the indicator that obtained the best 
performance in detecting the expulsion's occurrence was the welding force. Although, the availability of the force signal is limited in some types of welding machines.

Podržaj and Simončič [25] applied fuzzy logic to carry out online detection of expulsion in more recent studies. The signals of dynamic resistance, electrode displacement, and welding force were used as input data. It was observed that all entries are not necessary for all cases. For example, only the dynamic resistance was able to identify the expulsion in all samples tested for low carbon steel. The authors also pointed out that the dynamic resistance curve stands out for representing the physical phenomenon of spot-welding and its ease of measurement among the studied signals.

However, a calculation method that quantifies the presence of expulsion quickly and straightforwardly that could be applicable on the shop floor has not been observed in the literature. In this sense, to support the construction of the weldability lobe, required to develop a method to fit the best compromise between energy consumption and quality, this study proposed an indicator that quantifies the expulsion by analysing the dynamic resistance curve, already validated by Podržaj and Simončič [25] for low carbon steels.

Concerning the energy performance of the spot-welding process, Li et al. [26], [27] and Nagasathya et al. [29] analyse RSW machines' performance to convert energy. On the other hand, Zhou and Cai [30] address the energy efficiency of the weld nugget formation. However, neither of them proposed a method to quantify an efficiency indicator that considers machine conversion performance and the nugget formation. This indicator also will be proposed in this study, supporting the energy analysis of the RSW process. Carvalho and Gomes [31], De Oliveira Gomes et al. [33], and Balogun and Mativenga [1] evaluated and increased the energy efficiency of machining processes. Dehning et al. [34], in turn, used a multiple linear regression approach to identify and quantify factors influencing the energy intensity in automotive plants.

Nevertheless, despite the high energy consumption associated with the RSW process, only one study with a similar approach was found to correlate the resistance spot welding process's energy consumption reduction. Nie et al. [35] proposed a study to quantify the influence of process parameters simultaneously on quality and energy consumption. The authors proposed a "quality-energy consumption" balance model based on a Finite Element simulation. Although, its approach was not validated using empirical experiments.

In this study, therefore, a statistical investigation is used to evaluate the influence of the main configurable process parameter - welding current, welding time, and 
electrode force. Also, empirical experiments were conducted to build a weldability lobe. The energy consumption of different parameter combinations was analysed in the weldability lobe, where the quality is assured. Hence, energy labels to classify the process's energy performance was proposed to fit the best compromise between energy consumption and quality. The proposal of energy labels allows process parameter adjustments aiming at energy performance regulation according to production constraints.

\section{Materials \& Methods}

\subsection{Proposed expulsion indicator}

Following the methodology presented in literature [19] the $R_{\text {din }}$ curve calculation is performed using the RMS (root mean square) voltage and current measured in the weld clamp at each semi-cycle (Equation 2).

$$
R_{\text {din }_{t}}=\frac{V_{R M S_{t}}}{I_{R M S_{t}}}, \quad \text { para } t=1, \ldots, T
$$

where:

$\operatorname{Rdin}_{t}$ : Dynamic resistance calculated for semi-cycle $\mathrm{t}$.

$V_{R M S_{t}}$ : Secondary voltage RMS value for semi-cycle t.

$I_{R M S_{t}}:$ Secondary current RMS value for semi-cycle t.

$T:$ Total number of semi-cycles.

Considering the expulsion is characterized by an abrupt decay in the last stages of the dynamic resistance curve [36], a calculation method was proposed to identify this quantitative decay.

The first stages are expected to observe the minimum point of the curve $(\alpha)$, commonly preceded by decay (Figure 2). The analysis of the curves was carried out from the third cycle to avoid confusion between the decay due to the dynamic resistance curve before point $\alpha$ and the expulsion characteristic.

[Insert Figure 2 near here] 
Equation 3 is proposed to obtain a rate that characterizes the presence of expulsion. The abrupt decay characteristic of expulsion is observed in the literature between cycles. Therefore, as the calculation of the $R_{\text {din }}$ curve is performed for each semi-cycle. The equation is applied only to the odd values of the entire set of semi-cycles, obtaining an expulsion rate for each cycle, starting from the third cycle, corresponding to the fifth semi-cycle.

$$
T_{\exp _{t}}(\%)=\frac{\operatorname{Rdin}_{t}-\operatorname{Rdin}_{t-2}}{\operatorname{Rdin}_{t}} \times 100, \quad \text { parat }=5,7, \ldots, T
$$

After calculating the rates per cycle for each sample, the lowest value is identified. It represents the most significant expulsion that may have occurred during the manufacture of the weld. It is, therefore, the material expulsion indicator (Ex $\left.x_{\text {material }}\right)$ presented by Equation 4 .

$$
\operatorname{Ex}_{\text {material }}(\%)=\left|\min _{5 \leq t \leq T} T_{\exp _{t}}(\%)\right|
$$

Ex material quantifies the presence of expulsion. However, as it is a continuous indicator, it does not indicate whether it occurred or not. It is, therefore, necessary to define a limit value that represents whether the expulsion is significant or not. This limit is adjusted experimentally according to the operators' observations. After samples' manufacturing, the values of Ex material are calculated. The highest Ex material value in which operators did not observe a significant number of samples with expulsion is determined as the limiting value.

\subsection{Proposed total RSW energy efficiency indicator}

Approaches are presented for calculating the energy efficiency of conversion between primary and secondary [26],[27] and for calculating useful energy, which is actual energy used for the formation and growth of weld nugget [30]. However, no work was found to define RSW energy efficiency in terms of these two approaches simultaneously. 
For that matter, based on Carvalho and Gomes energy analysis for the machining process [31], the total RSW energy efficiency indicator $\left(E E_{\text {total }}\right)$ is proposed according to Equation 5. The proposal indicator considers both the energy efficiency of the machine and the energy performance of the process.

$$
E E_{\text {total }}=E E_{\text {machine }} \times E E_{\text {process }}
$$

where:

$E E_{\text {total }}:$ total RSW energy efficiency indicator.

$E E_{\text {machine }}:$ RSW machine energy efficiency.

$E E_{\text {process }}:$ RSW process energy efficiency indicator.

The calculation of RSW machine energy efficiency, $E E_{\text {machine }}$, [26], [27], is presented in Equation 6:

$$
E E_{\text {machine }}(\%)=\frac{E C_{\text {secondary }}}{E C_{\text {total }}} \times 100
$$

The calculation of the process energy efficiency indicator, based on [30], presents the coefficient of thermal energy efficiency for forming the weld point, $\rho(t)$. Equation 7 presents the relation of $\rho$ as a function of the total energy delivered to the system, corresponding to $E C_{\text {secondary }}$, and the $E_{\text {useful }}$ energy that is actually delivered for the formation of the nugget, at a time t. $E_{u s e f u l}$ is defined by the authors by Equation 8 as a function of the thermal energy transfer coefficient (C), nugget diameter (d) and penetration (h). Where $K_{h d}$ denotes the proportion between the diameter (d) and the penetration (h) of the weld nugget: $K_{h d}=2 \mathrm{~h} / \mathrm{d}$.

$$
\begin{gathered}
\rho(t)=\frac{E_{\text {useful }(t)}}{C E_{\text {secondary }(t)}} \\
E_{\text {útil }}=\frac{1}{4} C \pi d^{3} K_{h d}
\end{gathered}
$$


The calculation of the process efficiency could be defined by $\rho(t)$ itself. However, the calculation of the $E_{u s e f u l}$ as a function of the penetration of the weld, the nugget would require more significant experimental efforts, hindering the replicability of the proposed method in an industrial environment. For this reason, Equation 9 is proposed, in which are necessary the nugget diameter, obtained by the Pell test, widely used on the shop floor, and the measurement of the energy in the welding clamp. This relationship is given in $\mathrm{mm} / \mathrm{Wh}$ and represents an indicator of the process's energy efficiency.

$$
E E_{\text {process }}\left(\frac{m m}{W h}\right)=\frac{d_{\text {nugget }}}{C E_{\text {secondary }}}
$$

The calculation of the total energy efficiency indicator of the spot welding process, given by Equation 10, is obtained by replacing Equations 6 and 9 in Equation 5 .

$$
E E_{\text {total }}=\frac{d_{\text {nugget }}}{E C_{\text {total }}}
$$

By Equation 10 could be noted that when there is a reduction of energy consumption and the nugget diameter is keeping constant, the value of $E E_{\text {total }}$ increases as well. In the same way, by keeping energy consumption constant and increasing the nugget diameter, $E E_{\text {total }}$ also increases. The increase in the value of $E E_{\text {total }}$ represents that less energy was consumed to manufacture the weld point. The opposite analysis is also correct. In this sense, $E E_{\text {total }}$ presents itself as a valid indicator for comparing different process conditions when expressing whether sufficient or excess energy was used for a given nugget diameter.

\subsection{Experimental procedure}

In this section, the experimental procedure is explained. First, the RSW machine and the other support equipment used during the empirical performance are detailed. Following, energy and quality measurements are described, and lastly, software and procedures used during data processing and analysis are presented. 


\subsubsection{Samples' manufacturing}

Samples were manufactured following a complete 3-level full factorial design. The control factors (welding current, welding time, and electrode force), the material, and steel sheets thickness were determined by previous tests aiming to choose industry representatives values. Levels defined for each control factor are presented in Table 1.

[Insert Table 1 near here]

Galvanized steel sheets with $0.7 \mathrm{~mm}$ thickness were used as the base material. Its chemical composition is given in Table 2. The steel sheets were cut in $50 \times 30 \mathrm{~mm}$ rectangles, adopting linear overlapping according to Figure 3a. This positioning was guaranteed using a template made by additive manufacturing (3D printing) with $\mathrm{ABS}$ polymer (Acrylonitrile Butadiene Styrene) presented in Figure 3bc.

\section{[Insert Table 2 near here] \\ [Insert Figure 3 near here]}

Copper electrodes with a face diameter of $6.0 \mathrm{~mm}$ standardized according to DIN 44750 were used. A hand tool was used to mill the electrode after every 30 samples or if were identified craters on the electrodes' surface (Figure 4).

\section{[Insert Figure 4 near here]}

The empirical samples were conducted using a single-phase AC spot-welding machine (Düring Easy Line - CB150 - 85 kVA - $60 \mathrm{~Hz}$ ) with a manual clamp, a Harms $\&$ Wende Ratia 73 controller and equipped with a dedicated water-cooling system (SMC HRS060-AF-20) (Figure 5).

\section{[Insert Figure 5 near here]}

\subsubsection{Energy measurements}


The welding voltage and current signals from the primary transformers were collected during the experimental procedure. Primary measurement informs the amount of energy extracted directly from the power bus. This measurement is the actual consumption of the machine $\left(E C_{\text {total }}\right)$. Measurement of the current and voltage signals that pass through the welding clamp is also performed. These signals enable the calculation of how much energy was consumed to manufacture the spot weld disregarding the losses due to transformers energy conversion $\left(E C_{\text {secundary }}\right)$. These two consumptions allow discussions about the RSW machine's efficiency. The electrical energy associated with compressed air consumption to actuate the electrodes and the cooling unit is not considered in this study.

The measurement of energy consumption in the primary is performed using the energy analyser Embrasul RE6001 shown in Figure 6. The measurements are made on the electric cabinet. The energy analyser measures the voltage (V) and current (A), internally processes the data, and presents the consolidated power consumption (W) every 100 milliseconds.

\section{[Insert Figure 6 near here]}

All data were extracted using the ANL 60001 software available by Embrasul. Machine consumption during standby is negligible compared to the consumption during manufacture. So only the data related to the manufacture of the welds were selected.

To measure energy in the transformer's secondary side was needed to instrument the welding clamp, as illustrated in Figure 7. The instrumentation performed is based on previous studies [26], [27] and [29]. It includes installing voltage measurement wires installed near the electrodes on the mobile and fixed arms. Also, a Rogowski coil (Accuenergy - RCT16-1000) is attached to the welding clamp's bottom. The coil measures the intensity of the electromagnetic field. So, the current (I, in Amperes) can be obtained by integrating the signal measured by the coil (V, in Volts) multiplied by the inductance (M), according to Equation 11, where $t$ is the time in seconds (s). The inductance value depends on the coil's construction characteristics. It is obtained through calibration tests that use the welding current RMS values indicated by RSW controller software. In this study, M obtained was equal to 3,1227.

$$
I=M \int V d t
$$


Data acquisition was performed using Lynx ADS1800 via Ethernet communication. A sampling rate of $24 \mathrm{kHz}$ with a resolution of 24 bits was used. The high resolution was necessary due to the cutting of the sine wave at a frequency of $60 \mathrm{~Hz}$, due to the Silicon-Controlled Rectifier (SCR) circuit of the RSW machine to power control.

The calculation of energy in the secondary (in Wh) was done using Equation 12, where $\mathrm{V}$ is the voltage signal, in Volts (V), I is the current signal, in Amperes (A), and $\mathrm{t}$ is the time in seconds (s). The expression is divided by 3,600 to obtain the energy values in Wh.

$$
E C_{\text {secondary }}=\frac{\int V \times I d t}{3600}
$$

\subsubsection{Quality characterisation}

The welded samples' mechanical characterisation was performed by the Peel test and subsequent measurement of the nugget diameter. Peel test is widely used in the automotive industry for quality inspection. Equation 1 defines the minimum acceptable diameter for the welding nugget. Williams and Parker [11] observed the proper use of this equation for low carbon steels since, for this material, the weld shear resistance is proportional to the nugget diameter.

The test performed manually is shown in Figure 8. The nugget was measured with the aid of a calliper in two positions, $d_{1}$ and $d_{2}$. It seeks to measure the most extensive and most minor diameters of the circumference visually identified. The nugget diameter $(\mathrm{mm})$ is obtained by Equation 13.

$$
d_{\text {nugget }}=\frac{d_{1}+d_{2}}{2}
$$

[Insert Figure 8 near here] 


\subsubsection{Data processing and analysis}

All data gathered in the experiment were treated using the programming language Python 3.6. Statistical analysis, in turn, was performed using the RStudio version 1.1.453.

Statistical analyses were performed through graphical analysis of control factors' influence, followed by mathematical analysis by applying variance (ANOVA) analysis considering a $95 \%$ confidence interval. All analysis of variance were supported by residual analysis using the Shapiro-Wilk test.

After determining the control factors that have a relevant influence on the responses, linear models were proposed. The representativeness of the models was assessed by the adjusted R squared $\left(R_{a d j}^{2}\right)$ if the models are dependent on more than one variable. If dependent on only one variable, $\mathrm{R}$ squared $\left(R^{2}\right)$ should be used. The interpretation of the correlation coefficient is given in Table 3. Linear models, with correlation considered above moderate $(>0.51)$, have been validated. The validation of the models was made, considering the nominal value of the residual standard error (RSE) $[37,38]$.

[Insert Table 3 near here]

\subsection{Method to improve energy performance.}

After the execution of the experiment, the weldability lobe is determined. Its lower limit is defined by the minimum diameter of the weld nugget given by Equation 1. The definition of the upper limit is given by using a threshold of the indicator Ex material, which indicates whether the expulsion was significant. This threshold is adjusted experimentally according to the operators' observations.

Figure 9 shows a representation of the weldability lobe. The welding current and time were chosen to represent the axes due to this representation in the literature. The size of the circle presents in each combination of parameters expresses the size of the nugget. The colour scale represents energy consumption, and blue represents the lowest values, and red, the highest values. 
The total energy consumption $\left(E C_{\text {total }}\right)$ and the proposed total energy efficiency indicator $\left(E E_{\text {total }}\right)$, given by Equation 11, are analysed in the weldability lobe's range of parameters. So, intervals of parameters that resulted in similar values of $E C_{\text {total }}$ and $E E_{\text {total }}$ are determined, providing the proposition of energy labels.

The region with the best compromise between quality and energy consumption is shown by the highlight in green in Figure 9. In this region, the structural quality of the welded joints is guaranteed, the energy consumption is not considered excessive, and the total energy efficiency indicator shows its best result considering the quality criteria.

\section{Results and discussion}

\subsection{Statistical analysis}

One hundred sixty-eight samples were manufactured following a fully randomized 3-level full factorial design with three replicates. Control factors used in statistical analysis were the process parameters:

- Welding current $\left(C_{w e l}\right)$, in $\mathrm{kA}$;

- Welding time $\left(T_{w e l}\right)$, in cycles;

- Electrode fore $\left(F_{\text {ele }}\right)$, in kgf.

The following responses were analysed to understand the influence of the presented control factors on energy and quality performance:

- Total energy consumption $\left(E C_{\text {total }}\right)$;

- Nugget diameter $\left(d_{\text {nugget }}\right)$;

- RSW machine energy efficiency $\left(E E_{\text {machine }}\right)$;

- Proposed RSW total energy efficiency indicator $\left(E E_{\text {total }}\right)$.

Once some answers are dependent on the formation of the weld nugget diameter $-d_{\text {lentilha }}, E E_{\text {total }}$ - samples with interfacial failure mode were excluded to maintain a similar sampling environment for all analyses. The absence of these samples does not affect the results since they are not interesting for the industry as they compromise the automotive body's structural integrity. To maintain the DoE balance, the control factor levels that have generated welds with interfacial failure mode (welding currents of 6 and 
$7 \mathrm{kA}$ ) were excluded. Thus, the sample set was reduced from 168 to 120 . In addition to the application of ANOVA, linear models were proposed for each of the responses.

\section{[Insert Table 4 near here]}

Table 4 shows a summary of the statistical analysis. The first column is the entrance with analysed responses, and the following columns are the results with a description of the influences of the control factors for each response. Where " $\uparrow$ " represents directly proportional influence, “ $\downarrow$ ” inversely proportional, and “-” none influence. The next column presents the adjusted correlation coefficient for the proposed models. Finally, in the last two columns, residual standard errors are shown in the response unit and percentage $(\%)$.

\section{[Insert Table 4 near here]}

The predictive models of the analysed responses: $E C_{\text {total }}, d_{\text {nugget }}, E E_{\text {machine }}$ and $E E_{\text {total }}$ are presented, respectively, in the following Equations 14, 15, 16, and 17.

$$
\begin{aligned}
& E C_{\text {total }}=1.98 \times 10^{-1}+2.58 \times 10^{-2} \times C_{\text {wel }} \times T_{\text {wel }} \\
& d_{\text {nugget }}=3.53+1.57 \times 10^{-3} \times{C_{\text {wel }}}^{2} \times T_{\text {wel }}+2.78 \times 10^{-4} \times T_{\text {wel }} \times F_{\text {ele }} \\
&+5.67 \times 10^{-4} \times C_{\text {wel }} \times F_{\text {ele }}-7.41 \times 10^{-5} \times C_{\text {wel }} \times T_{\text {wel }} \\
& \times F_{\text {ele }} \\
& \\
& E E_{\text {machine }}=17.56+0.61 \times C_{\text {wel }}+0.18 \times T_{\text {wel }} \\
& E E_{\text {total }}= 6.56-4.79 \times 10^{-3} \times C_{\text {wel }}^{2}-3.26 \times 10^{-3} \times T_{\text {wel }}^{2}-\frac{1.40}{T_{\text {wel }}}
\end{aligned}
$$


The welding current and time influenced all analysed responses. The electrode force, on the other hand, had a relevant influence only on the nugget diameter. Furthermore, high-level correlation linear models were obtained as a function of the process parameters for the total energy consumption and the total efficiency indicator proposed in this work. Hence, these models could directly assist in decision-making seeking energy and cost savings. For the other answers, were obtained models with moderate $\mathrm{R}_{\mathrm{adj}}^{2}$. Still, RSE (\%) for all models was below $9 \%$.

\subsection{RSW's energy performance}

The dynamic resistance for each sample was calculated by using the data measured in the secondary. From them, the proposed expulsion indicator (Ex $\left.x_{\text {material }}\right)$ was calculated as well (Table 5).

[Insert Table 5 near here]

To characterize the upper limit of the weldability lobe, the expulsion indicator (Ex $\left.x_{\text {material }}\right)$ was analysed. A comparison was made with the operators' observations. Figure 10 presents a boxplot with the values obtained for the material expulsion indicator separated into two groups: "0", samples in which no material expulsions were observed, and, otherwise, "1". It is possible to notice that the Ex material's means for presence and absence of expulsion are different. To support this observation, the Welch test was applied to compare the means since the variances between the groups are different. The Welch test has a p-value of less than $2.20 \times 10^{-16}$, proving at $95 \%$ confidence that the means are different. With this, the use of the indicator is validated.

[Insert Figure 10 near here]

It is also possible to note that all samples in which expulsion was not observed during manufacture have values below 3\%. Most samples in which expulsion was 
observed showed an indicator above this value. That said, the threshold of $3 \%$ was used as a weldability lobe's upper limit.

The weldability lobe's lower limit, on the other hand, was defined by Equation 1. The minimum diameter to achieve quality for the experiments carried out in this work is $4.2 \mathrm{~mm}$. Since the linear model data will be used, its error was added to the weldability lobe's lower limit, making it $4.53 \mathrm{~mm}$.

The weldability lobe was obtained by applying the lower $\left(d_{\text {nugget }}>4,53 \mathrm{~mm}\right)$ and upper limits $\left(E x_{\text {material }}<3 \%\right)$ to the sample space under study: 8 to $12 \mathrm{kA}, 8$ to 20 cycles and 226 and $343 \mathrm{kgf}$. The nugget diameter prediction model was used to characterize the sample space. It was observed that all samples have a nugget diameter greater than the lower limit.

The determination of the upper limit was made by observing the values of $E x_{\text {material }}$ presented for each sample (Table 5). The combinations of parameters in which at least two of the three samples produced had Ex material $<3 \%$ were considered to with no expulsion.

The weldability lobe, therefore, comprises the intervals in which combinations of parameters were found that respect the proposed quality criteria:

- $\quad C_{w e l}: 8 \mathrm{kA}, T_{\text {wel }}: 20$ cycles, $F_{\text {ele }}: 226 \mathrm{kgf}$;

- $C_{w e l}: 8 \mathrm{kA}, T_{w e l}: 8$ to 20 cycles, $F_{\text {ele }}: 343 \mathrm{kgf}$;

- $C_{w e l}: 9 \mathrm{kA}, T_{w e l}: 8$ to 16 cycles, $F_{e l e}: 343 \mathrm{kgf}$;

- $C_{w e l}: 11 \mathrm{kA}, T_{w e l}: 8$ cycles, $F_{e l e}: 343 \mathrm{kgf}$.

In Figure 11, the size of the circle presents in each combination of parameters expresses the size of the nugget. The linear model achieved in section 4.1 to represent nugget diameter in terms of the process parameters (Equation 15) was used to estimate the nugget diameter for all parameters combination. The combinations that obtained Ex $x_{\text {material }}<3 \%$ are highlighted in green, and the others in red. As the entire analyzed interval presented nugget diameters higher than the minimum limit, the weldability lobe comprises the combinations of parameters highlighted in green.

[Insert Figure 11 near here] 
The predictive models of total energy consumption and energy efficiency indicator, both proposed in Section 4.1, were analysed inside the weldability lobe. The variation in the values of $E C_{\text {total }}$ in relation to $E E_{\text {total }}$ means that it is possible to obtain different energy consumption for the same value of the total energy efficiency indicator. For this reason, it is essential to analyse the two indicators together. The behaviour is shown in Table 6 for $F_{\text {ele }}=226 \mathrm{kgf}$, and in Table 7 for $F_{\text {ele }}=343 \mathrm{kgf}$.

\section{[Insert Table 6 near here]}

[Insert Table 7 near here]

It was defined ranges for each variable. The range variation for total energy consumption was $0.5 \mathrm{Wh}$ and for energy efficiency, $0.2 \mathrm{~mm} / \mathrm{Wh}$. For each combination between the $E C_{\text {total }}$ range and $E E_{\text {total }}$, an energy label from $\mathrm{A}$ to $\mathrm{M}$ was generated. In which A represents the combinations with the best energy performance and $\mathrm{M}$, the opposite. The prioritization order for the parameter combinations to generate the energy labels was: first, the lowest energy consumption, and second, the highest indicator of total energy efficiency.

Figure 12 illustrates energy label application in the contour lines of the predicted models for total energy consumption (a) and total energy efficiency indicator (b). The set of parameters that presents the best compromise between quality and energy performance was presented in Figure 13. The highlighted region is the one with the highest energy efficiency index, the lowest energy consumption, and meets the quality criteria:

- $C_{w e l}: 8 \mathrm{kA}, T_{w e l}: 8$ cycles, $F_{\text {ele }}: 343 \mathrm{kgf}$.

The energy labels proposal allows flexibility to choose parameter combinations with different levels of energy performance depending on the shop floor restrictions.

\section{[Insert Figure 12 near here] \\ [Insert Figure 13 near here]}

Although electrode force does not directly influence energy consumption and energy efficiency, it influences the quality, so it indirectly supports the choice of the compromise solution since it alters the region of the weldability lobe. 
It was not possible to obtain a linear model that represents the material expulsion indicator $\left(E x_{\text {material }}\right)$ essential to the weldability lobes' upper limiting definition. The other responses $\left(E C_{\text {total }}, d_{\text {nugget }}\right.$ and $\left.E E_{\text {total }}\right)$ can be obtained by the linear models presented in section 4.1, as long as the boundary conditions are maintained the same in this study. Otherwise, the experiments must be performed entirely again.

The proposed compromise solution results in energy consumption of approximately $2 \mathrm{Wh}$ /spot-weld. Due to the lack of non-destructive inspection methods, it is common to use higher process parameters that result in more energy consumed. However, no references were found to quantify the average spot welding process' consumption in the automotive industry. To estimate this number, a scenario analysis was performed based on the values obtained experimentally in this study to quantify the benefits of the compromise solution.

Two scenarios were analysed, one bold and the other, conservative. The first considers the industrial average to be $3.8 \mathrm{Wh} / \mathrm{spot}$-weld. This value is equivalent to the average consumption of all points that presented satisfactory quality for the industrial criterion $\left(d_{\text {nugget }}>4.53 \mathrm{~mm}\right)$, including those that presented expulsion. The conservative, in turn, considers the average consumption only of the points inserted in the weldability lobe $\left(d_{\text {nugget }}>4.53 \mathrm{~mm}\right.$ and Ex material $\left.<3 \%\right)$. For this scenario, the industrial average was $3 \mathrm{Wh} /$ spot-weld.

Therefore, considering the sample space used in this study, the compromise solution reduces $47 \%$ concerning the bold scenario and $33 \%$ to the conservative scenario. Extrapolating these percentages to the Brazilian industry in which approximately 10 billion welding points are produced per year in the automotive sector, Figure 14 is obtained. It shows the annual consumption for each energy label, considering the highest value of the energy consumption range multiplied by 10 billion spot welds manufactured annually. Thus, it is possible to have a notion about the impact to use different labels.

Note that some labels have the same consumption, as is B, C, and D. However, they differ because they have different nugget diameters. As a result, there are different energy efficiency indicators $\left(E E_{\text {total }}\right)$ presented below the horizontal axis of the graph.

[Insert Figure 14 near here] 
Still, in Figure 14, the annual consumption is highlighted by dashed horizontal lines using the dark green for the compromise solution, $20 \mathrm{GWh}$; red for bold scenery, 38 GWh; and light green for the conservative, $30 \mathrm{GWh}$. Savings of $10 \mathrm{GWh}$ per year are projected using the conservative scenario. Compared to the bold scenario, this savings reaches $18 \mathrm{GWh}$. Applying these savings in the scope of the automotive industry, which uses 4,000 to 6,000 welding points per car, considering an average monthly volume of 10,000 cars, it is possible to obtain a monthly reduction from $50 \mathrm{MWh}$ (conservative scenario) to $90 \mathrm{MWh}$ (bold scenario).

\section{Conclusions}

The aim of this research was the development of a methodology to improve the energy performance of the RSW process without compromising its quality, thus reducing its carbon footprint. To support the quality investigation, this study proposed an indicator that quantifies the expulsion by analysing the dynamic resistance curve, Ex material . Energy analysis is supported by the proposition of an energy efficiency indicator, $E E_{\text {total }}$, that considers simultaneously the efficiency of the machine energy conversion and the efficiency for the weld nugget formation and growth.

Moreover, statistical analyses performed measured the influence of the control factors - welding current $\left(C_{w e l}\right)$, welding time $\left(T_{w e l}\right)$ and electrode force $\left(F_{\text {ele }}\right)-$ on the total energy consumption $\left(E C_{\text {total }}\right)$, nugget diameter $\left(d_{\text {nugget }}\right)$, RSW machine energy efficiency $\left(E E_{\text {machine }}\right)$ and proposed total RSW efficiency indicator $\left(E E_{\text {total }}\right)$. Linear models have been developed for all responses. Models that predict energy consumption $\left(E C_{\text {total }}\right)$ and the total RSW energy efficiency indicator $\left(E E_{\text {total }}\right)$ presented a very high adjusted correlation, 0.97 e 0.92 , respectively. The proposition of linear models is essential because it allows predicting energy and quality to support adjustments in the welding line setting.

Energy consumption and energy efficiency were analysed in the weldability lobe. Thirteen energy labels have been proposed. They classify energy performance from the best (A) to the worst (M). In this way, process parameters with adequate energy performance for production restrictions can be chosen.

The best compromise solution for the parameter range studied in this work was: $C_{w e l}: 8 \mathrm{kA}, T_{w e l}: 8$ cycles and $F_{\text {ele }}: 343 \mathrm{kgf}$. The compromise solution results in a 
consumption of approximately $2 \mathrm{Wh}$ /spot-weld. Comparing this result with two proposed scenarios, one bold and the other conservative. There is a saving of 33\% for the conservative scenario and $47 \%$ in the bold one. In the automotive sector monthly production volume of 10,000 cars, represents a reduction from $50 \mathrm{MWh}$ (conservative) to $90 \mathrm{MWh}$ (bold). Considering a production volume of 10,000 cars per month, it represents a reduction from $50 \mathrm{MWh}$ (conservative) to $90 \mathrm{MWh}$ (bold).

The results obtained in this work are applied to the analysed sample space that comprises the range of process parameters, the material, the thickness, and the number of welded sheets. However, the method developed can be applied to other conditions. Likewise, although the work was performed on a single-phase AC RSW machine, the developed method can be replicated on a medium-frequency DC RSW machine.

\section{Declarations}

\section{Funding}

This study was part of a master thesis in the Technological Institute of Aeronautics (ITA) funded by CAPES (Coordination for the Improvement of Higher Education Personnel).

\section{Conflict of Interest}

The authors declare that they have no conflict of interest.

\section{Availability of data and material}

Not applicable

\section{Code availability}

Not applicable

\section{References}

1. Balogun VA, Mativenga PT (2013) Modelling of direct energy requirements in mechanical machining processes. J Clean Prod 41:179-186. https://doi.org/10.1016/j.jclepro.2012.10.015

2. International Energy Agency (IEA) (2018) Energy efficiency 2018: Analysis and outlooks to 2040 
3. Conti J, Holberg P, Diefenderfer J, et al (2016) International energy outlook 2016 with projections to 2040. Washington

4. Introna V, Cesarotti V, Benedetti M, et al (2014) Energy Management Maturity Model: An organizational tool to foster the continuous reduction of energy consumption in companies. J Clean Prod 83:108-117. https://doi.org/10.1016/j.jclepro.2014.07.001

5. International Organization for Standardization (ISO) (2011) ABNT NBR ISO 50001:2011 - Sistemas de gestão da energia - Requisitos com orientações para uso

6. Daudt G, Willcox LD (2018) Indústria Automotiva. VISÃO 2035 Bras país desenvolvido - Agendas setoriais para o Desenvolv 183-208

7. International Organization of Motor Vehicle Manufacturers (OICA) (2020) 2018 Production Statistics. http://www.oica.net/category/production-statistics/2018-statistics/. Accessed 6 Apr 2020

8. Empresa de Pesquisa Energética (EPE) (2019) Balanço Energético Nacional 2019. Rio de Janeiro

9. Li YB, Lin ZQ, Shen Q, Lai XM (2011) Numerical analysis of transport phenomena in resistance spot welding process. J Manuf Sci Eng Trans ASME 133:1-8. https://doi.org/10.1115/1.4004319

10. Boersch I, Füssel U, Gresch C, et al (2018) Data mining in resistance spot welding. Int J Adv Manuf Technol 99:1085-1099. https://doi.org/10.1007/s00170-016-9847-y

11. Williams NT, Parker JD (2004) Review of resistance spot welding of steel sheets Part 1 Modelling and control of weld nugget formation.

https://doi.org/10.1179/095066004225010523

12. Runnemalm A, Ahlberg J, Appelgren A, Sjökvist S (2014) Automatic inspection of spot welds by thermography. J Nondestruct Eval 33:398-406.

https://doi.org/10.1007/s10921-014-0233-0

13. Zhang H (1999) Expulsion and its influence on weld quality. Weld J (Miami, Fla) 78:373-s

14. Lee SR, Choo YJ, Lee TY, et al (2001) A quality assurance technique for resistance spot welding using a neuro-fuzzy algorithm. J Manuf Syst 20:320-328.

https://doi.org/10.1016/S0278-6125(01)80051-0

15. El-Banna M, Filev D, Chinnam RB (2008) Online qualitative nugget classification by using a linear vector quantization neural network for resistance spot welding. Int J Adv Manuf Technol 36:237-248. https://doi.org/10.1007/s00170-006-0835-5

16. ISO (2006) ISO 10447:2006 - Resistance welding - Peel and chisel testing of resistance spot and projection welds. 6

17. Fan Q, Xu G, Gu X (2016) Expulsion characterization of stainless steel resistance spot welding based on dynamic resistance signal. J Mater Process Technol 236:235-240. https://doi.org/10.1016/j.jmatprotec.2016.05.026

18. Podržaj P, Polajnar I, Diaci J, Kariž Z (2004) Expulsion detection system for resistance spot welding based on a neural network. Meas Sci Technol 15:592-598. https://doi.org/10.1088/0957-0233/15/3/011

19. Podržaj P, Polajnar I, Diaci J, Kariž Z (2004) Expulsion detection system for resistance spot welding based on a neural network. Meas Sci Technol 15:592-598.

https://doi.org/10.1088/0957-0233/15/3/011 
20. Farson DF, Chen JZ, Ely K, Frech T (2003) Monitoring of expulsion in small scale resistance spot welding. Sci Technol Weld Join 8:431-436.

https://doi.org/10.1179/136217103225009071

21. Bhole SD, Ma C, Khan MS, Chen D (2011) A Study of Spot Welding of Advanced High Strength Steels for Automotive Applications. J Iron Steel Res Int 18:724-729

22. Jou M (2003) Real time monitoring weld quality of resistance spot welding for the fabrication of sheet metal assemblies. J Mater Process Technol 132:102-113. https://doi.org/10.1016/S0924-0136(02)00409-0

23. Matsushita M, Ikeda R, Oi K (2015) Development of a new program control setting of welding current and electrode force for single-side resistance spot welding. Weld World 59:533-543. https://doi.org/10.1007/s40194-015-0228-1

24. Luo Y, Li J, Wu W (2013) Characterization of nugget nucleation quality based on the structure-borne acoustic emission signals detected during resistance spot welding process. Meas J Int Meas Confed 46:1053-1060. https://doi.org/10.1016/j.measurement.2012.11.016

25. Podržaj P, Simončič S (2011) Resistance spot welding control based on fuzzy logic. Int J Adv Manuf Technol 52:959-967. https://doi.org/10.1007/s00170-010-2794-0

26. Li W, Feng E, Cerjanec D, Grzadzinski GA (2004) Energy Consumption in AC and MFDC. Sheet Met Weld Conf XI 1-12

27. Li W, Cerjanec D, Grzadzinski GA (2005) A comparative study of single-phase AC and multiphase DC resistance spot welding. J Manuf Sci Eng Trans ASME 127:583-589. https://doi.org/10.1115/1.1949621

28. Nagasathya N, Boopath SR, Santhakumari A (2013) An Energy efficient Adaptive technology for Welding of Thin Sheets. 2013 Int Conf Energy Effic Technol Sustain 901-906. https://doi.org/10.1109/ICEETS.2013.6533507

29. Nagasathya N, Boopath SR, Santhakumari A (2013) MFDC - An Energy efficient Adaptive technology for Welding of Thin Sheets. 2013 Int Conf Energy Effic Technol Sustain 901-906. https://doi.org/10.1109/ICEETS.2013.6533507

30. Zhou K, Cai L (2014) On the development of nugget growth model for resistance spot welding. J Appl Phys 115:. https://doi.org/10.1063/1.4872247

31. Carvalho HMB de, Gomes J de O (2015) Energy Efficiency Evaluation for Machining Process in Flexible Manufacturing Systems - A Case Study. Procedia CIRP 29:40-44. https://doi.org/10.1016/j.procir.2015.02.196

32. De Oliveira Gomes E V, De Oliveria Gomes J, Grote K-H (2013) Discrete Event Simulation Inserted into Kaizen Event to Assess Energy Efficiency. 20th CIRP Int Conf Life Cycle Eng 499-503. https://doi.org/10.1007/978-981-4451-48-2_81

33. Gomes VEDO, Gomes JDO, Grote KH (2013) Discrete event simulation inserted into kaizen event to assess energy efficiency. In: Nee AYC, Song B, Ong S-K (eds) ReEngineering Manufacturing for Sustainability - Proceedings of the 20th CIRP International Conference on Life Cycle Engineering. Springer Singapore, Singapore, pp 499-503

34. Dehning P, Thiede S, Mennenga M, Herrmann C (2017) Factors influencing the energy intensity of automotive manufacturing plants. J Clean Prod 142:2305-2314. https://doi.org/10.1016/j.jclepro.2016.11.046

35. Nie X, Zhu W, Cai H, Chen H (2018) Optimization of resistance spot welding 
parameters based on load of welding spot. Hanjie Xuebao/Transactions China Weld Inst 39:114-120

36. Dickinson DW, Franklin JE, Stanya A (1980) Characterization of Spot Welding Behavior by Dynamic Electrical Parameter Monitoring The use of two parametersdynamic resistance and critical expulsion energy-is proposed for controlling resistance spot welding

37. Montgomery DC (2012) Design and Analysis of Experiments Eighth Edition

38. Hinkle D, Wiersma W, Jurs S (2003) Applied Statistics for the Behavioral Sciences, 5th ed. Houghton Mifflin, Boston 


\section{Figures}

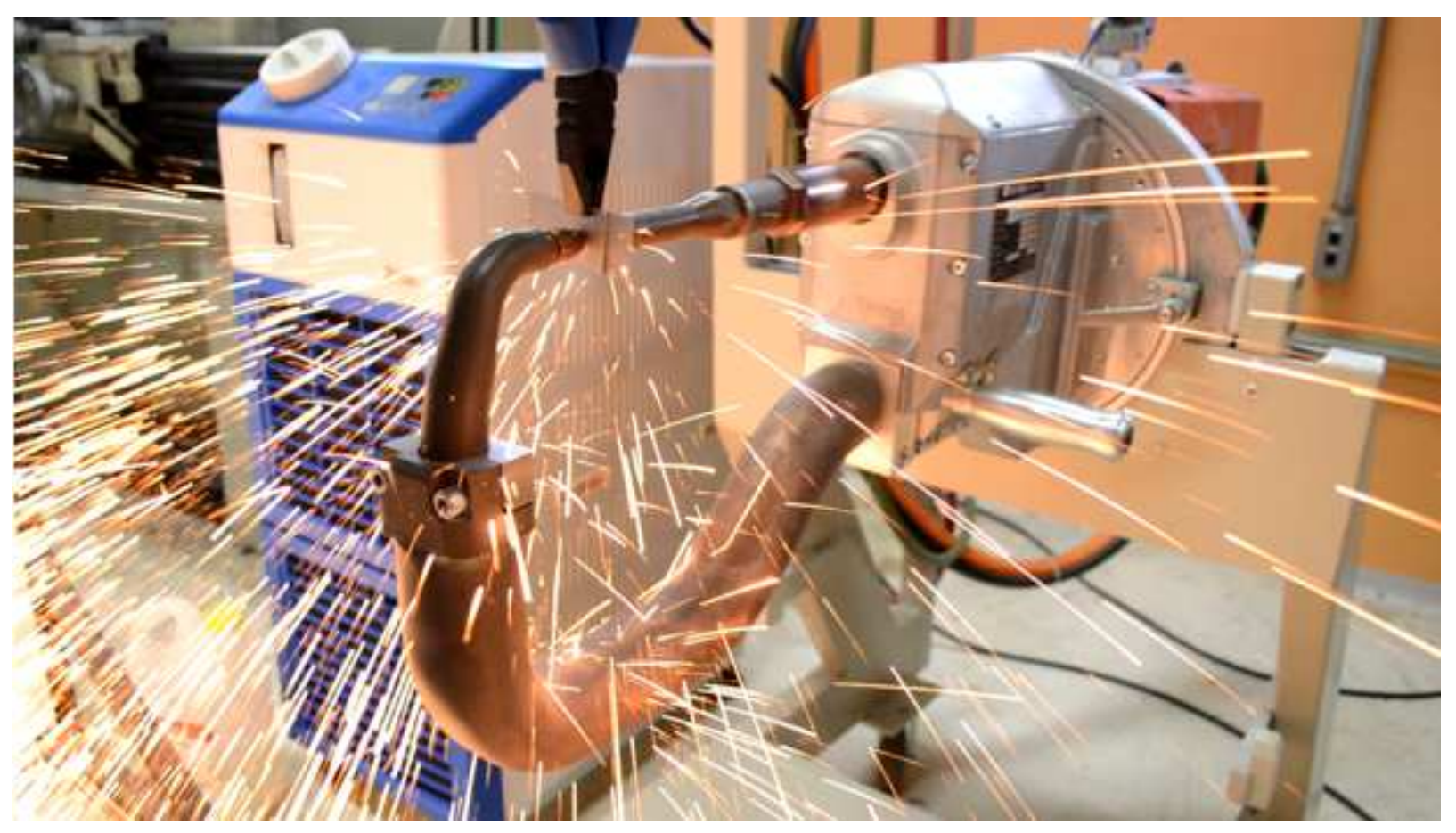

Figure 1

Occurrence of material expulsion during spot weld production.

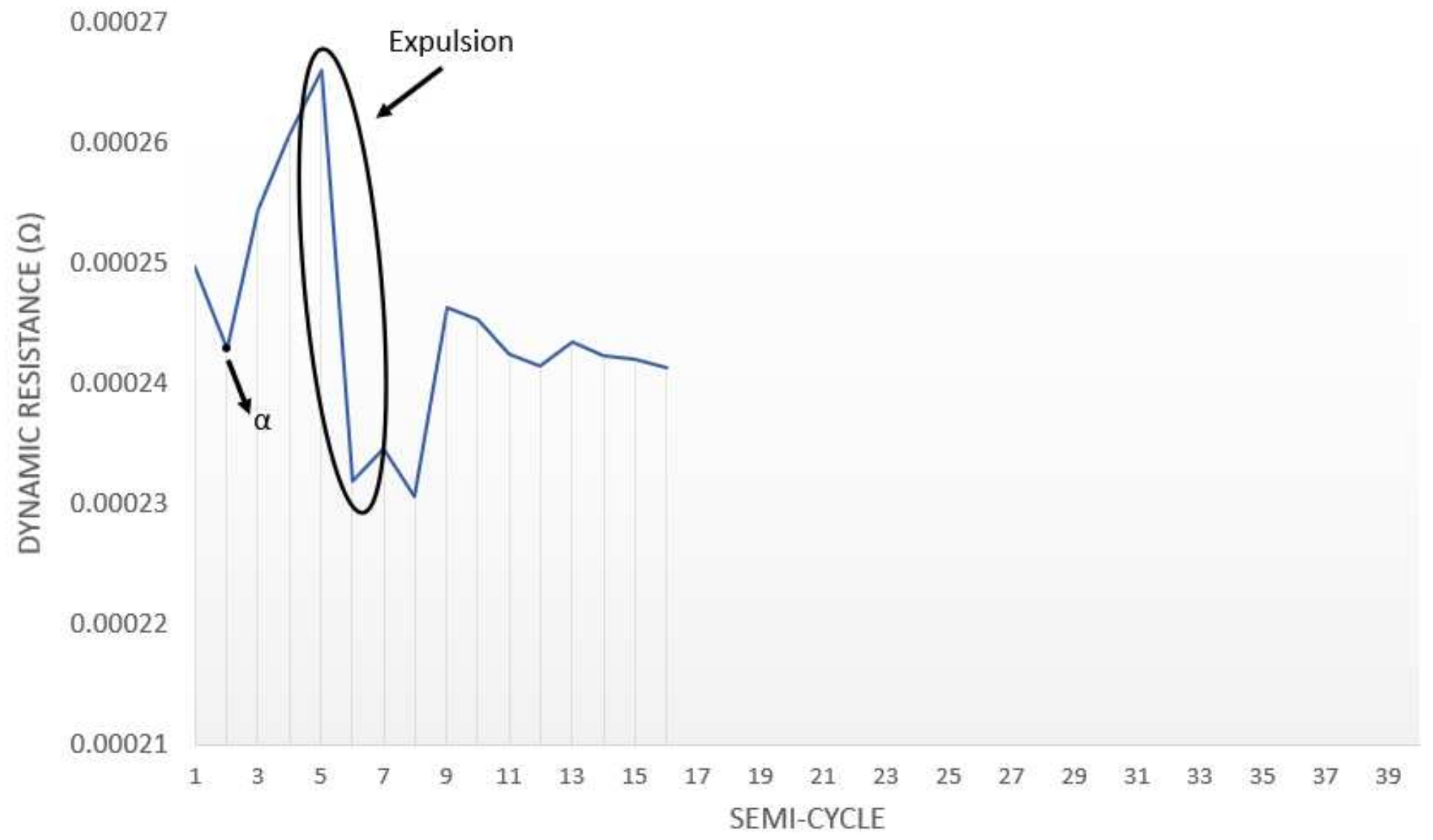


Figure 2

Dynamic resistance curve.
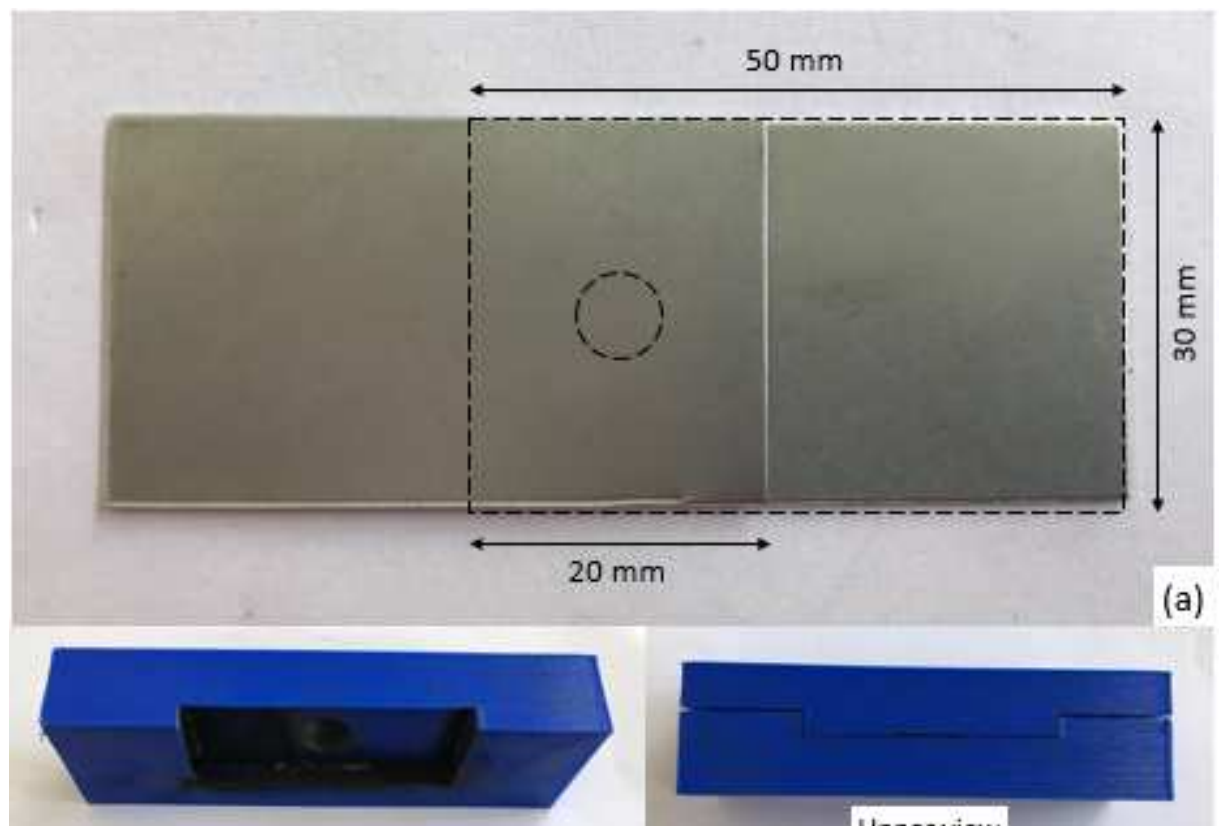

(a)
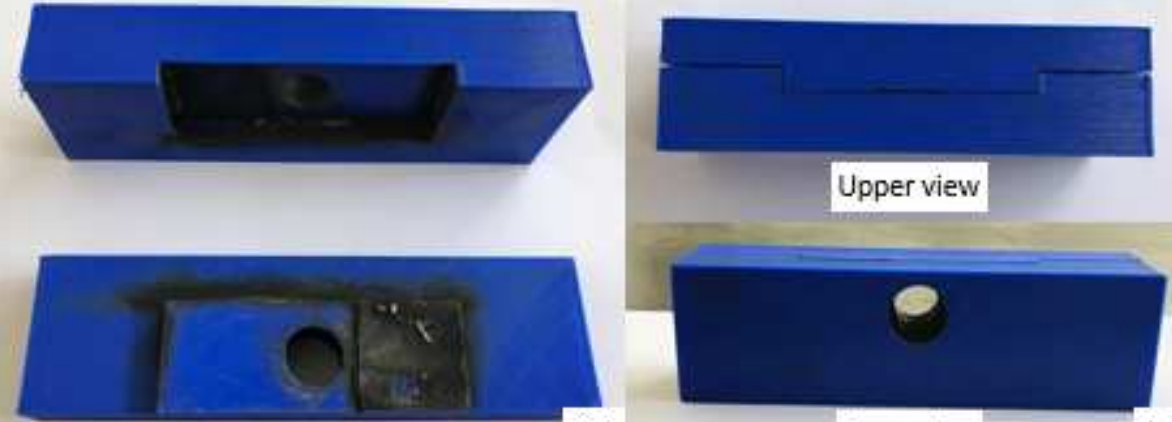

Upper view

(b)

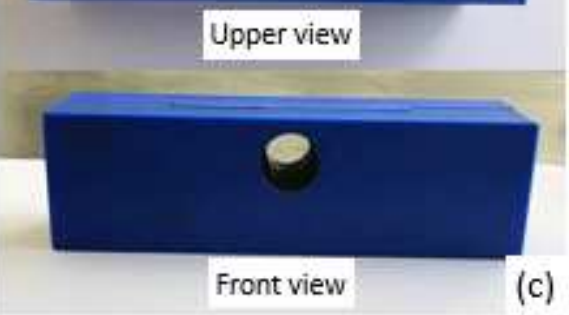

Figure 3

(a) Linear overlapping positioning of the CR4 steel sheets. Template printed in ABS polymer. (b) Open template, the dark parts in the surface are the result of material expulsion during the experiment. (c) Upper and front views of the template. 


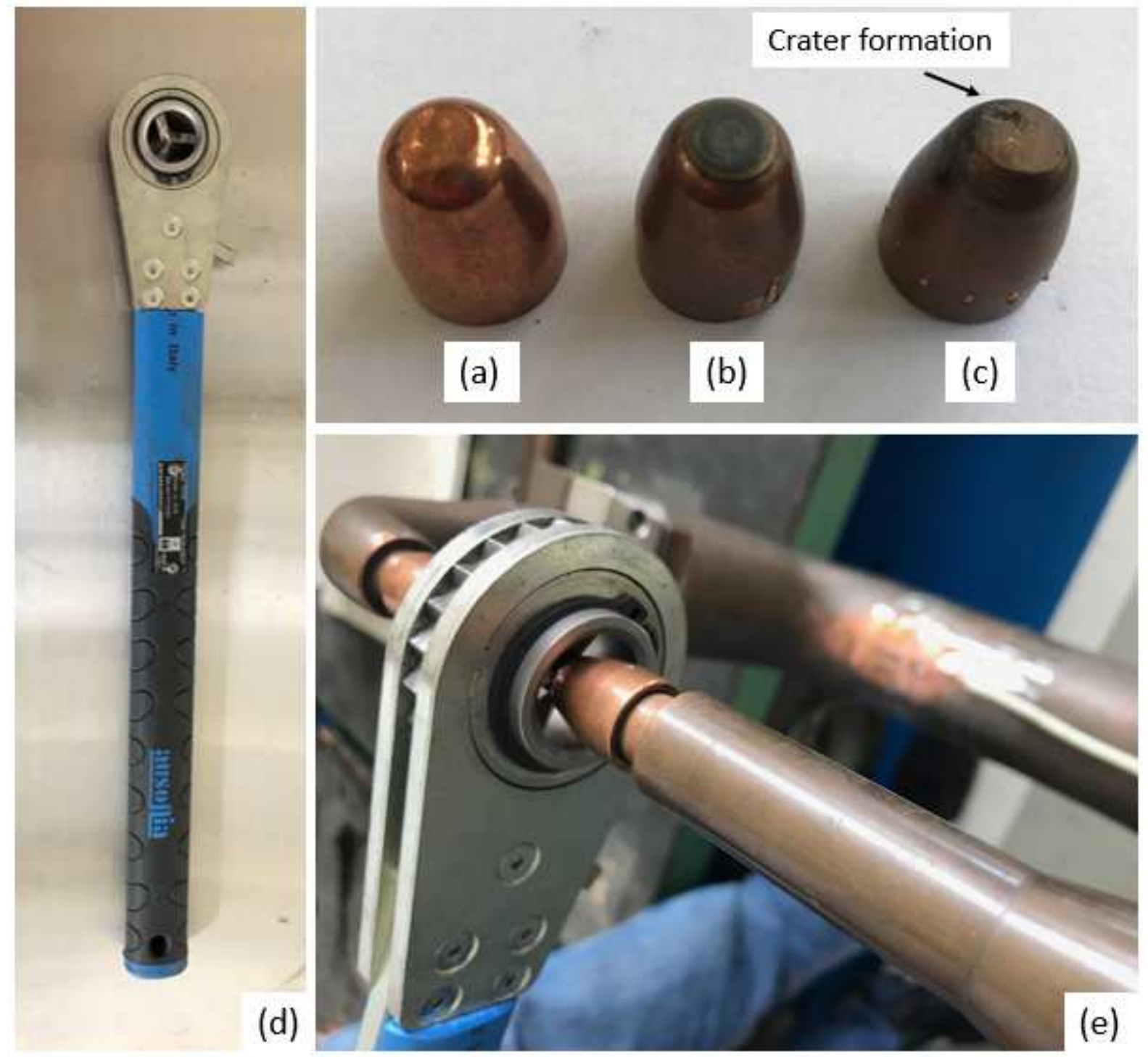

\section{Figure 4}

Wear of the electrode face and milling operation. In (a) a brand-new electrode, in (b) a used electrode but in good condition, in (c) an electrode with crater formation. In (d), a hand tool for milling operation, and in (e), the milling operation's execution is represented. 


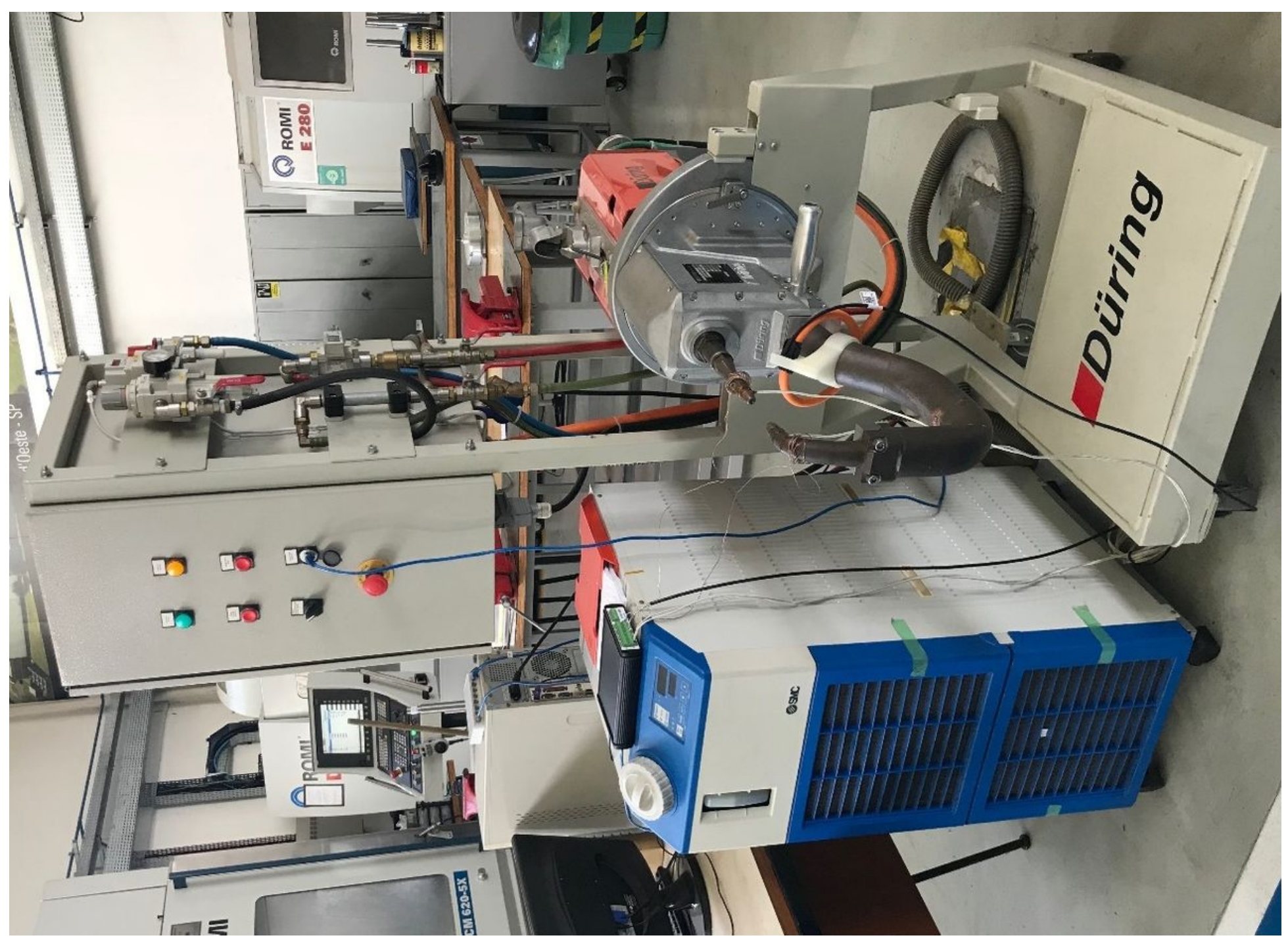

Figure 5

Spot-welding machine (Düring Easy Line - CB150 - 85 kVA) and a dedicated cooling unit (SMC HRS060AF-20). 


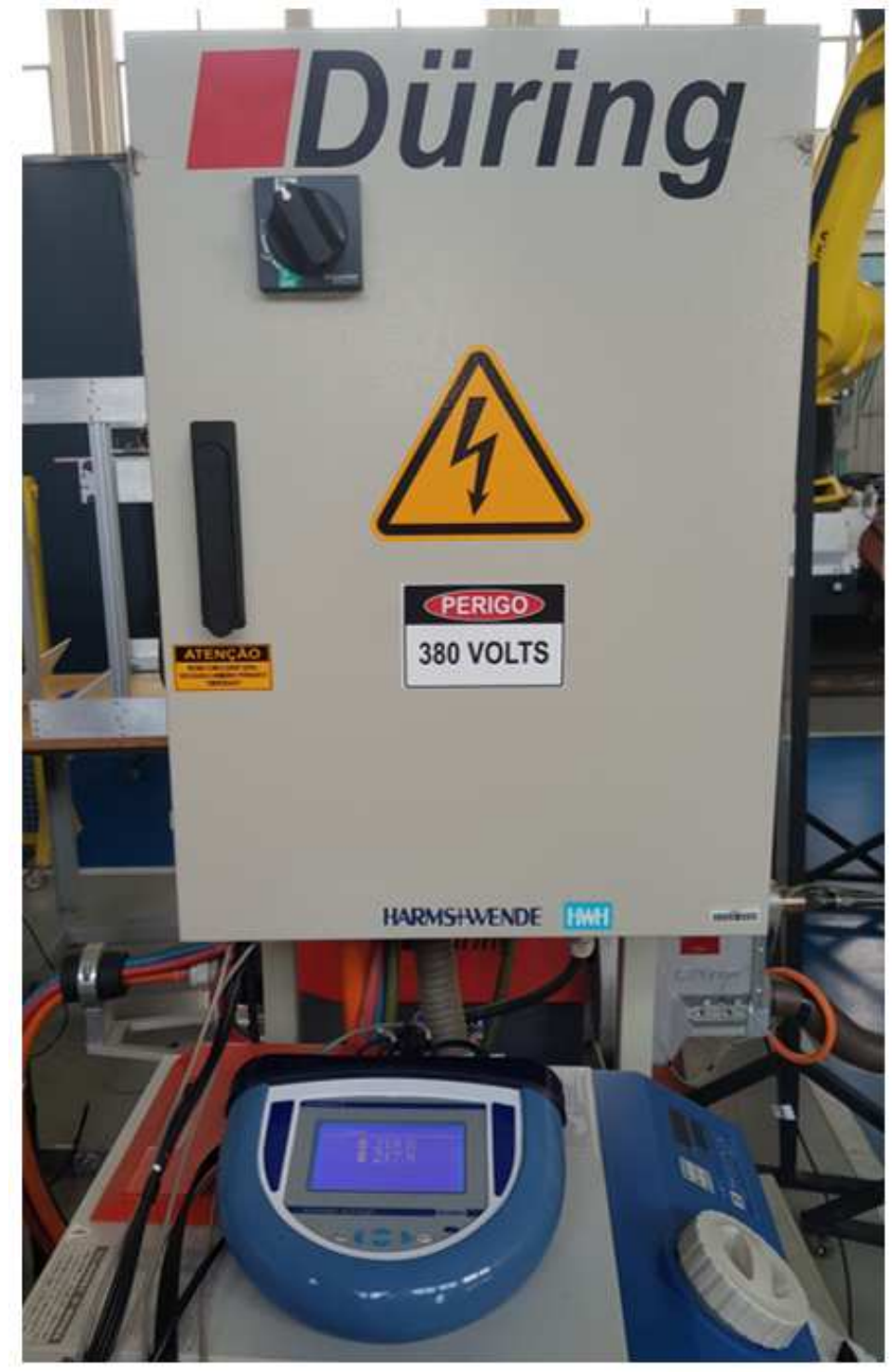

(a)

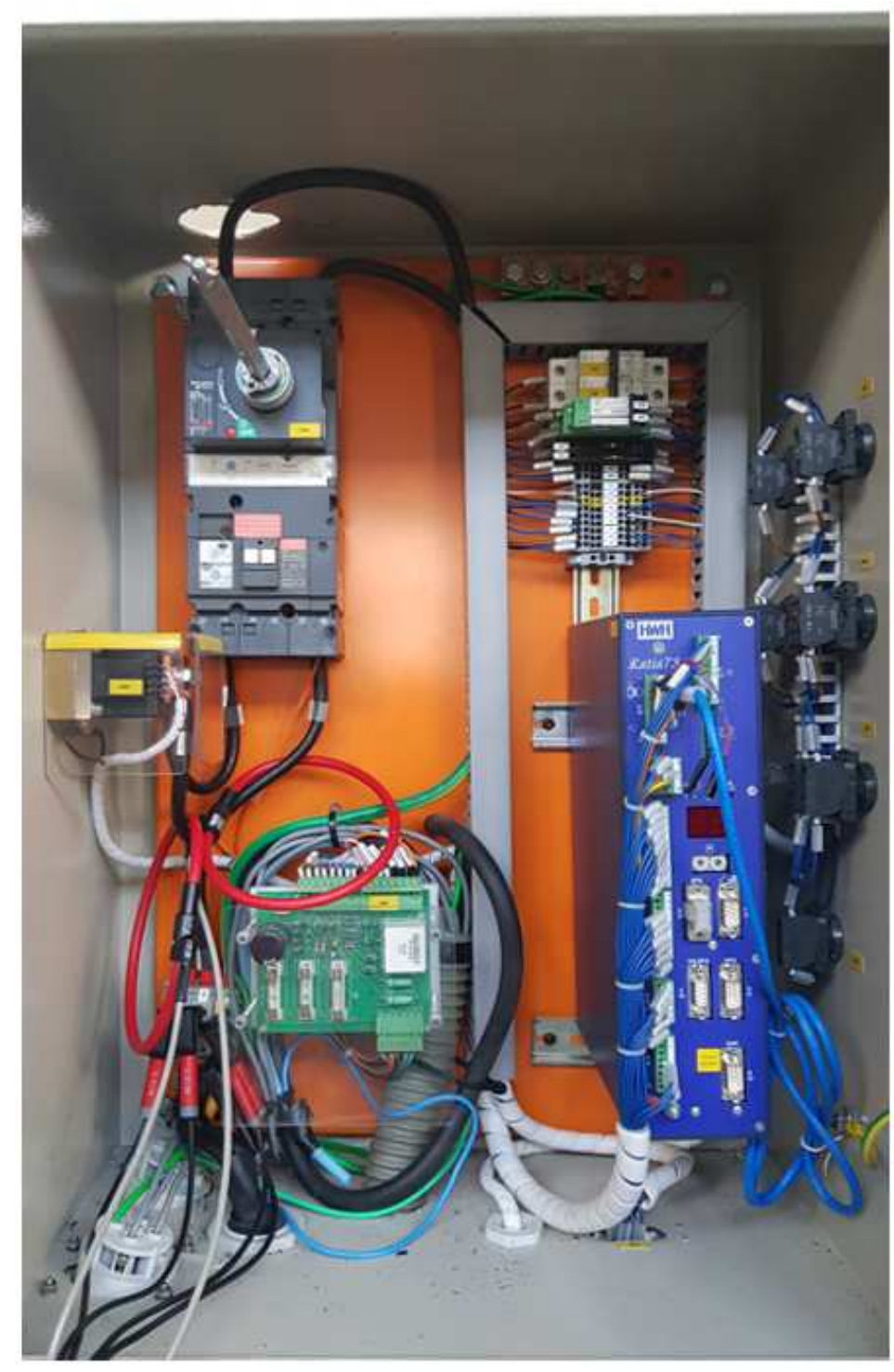

(b)

Figure 6

Energy measurement on the primary side of the transformers. In (a) is presented energy analyser Embrasul RE6001 and in (b), the terminal's configuration of voltage (V) and current (A) signals. 


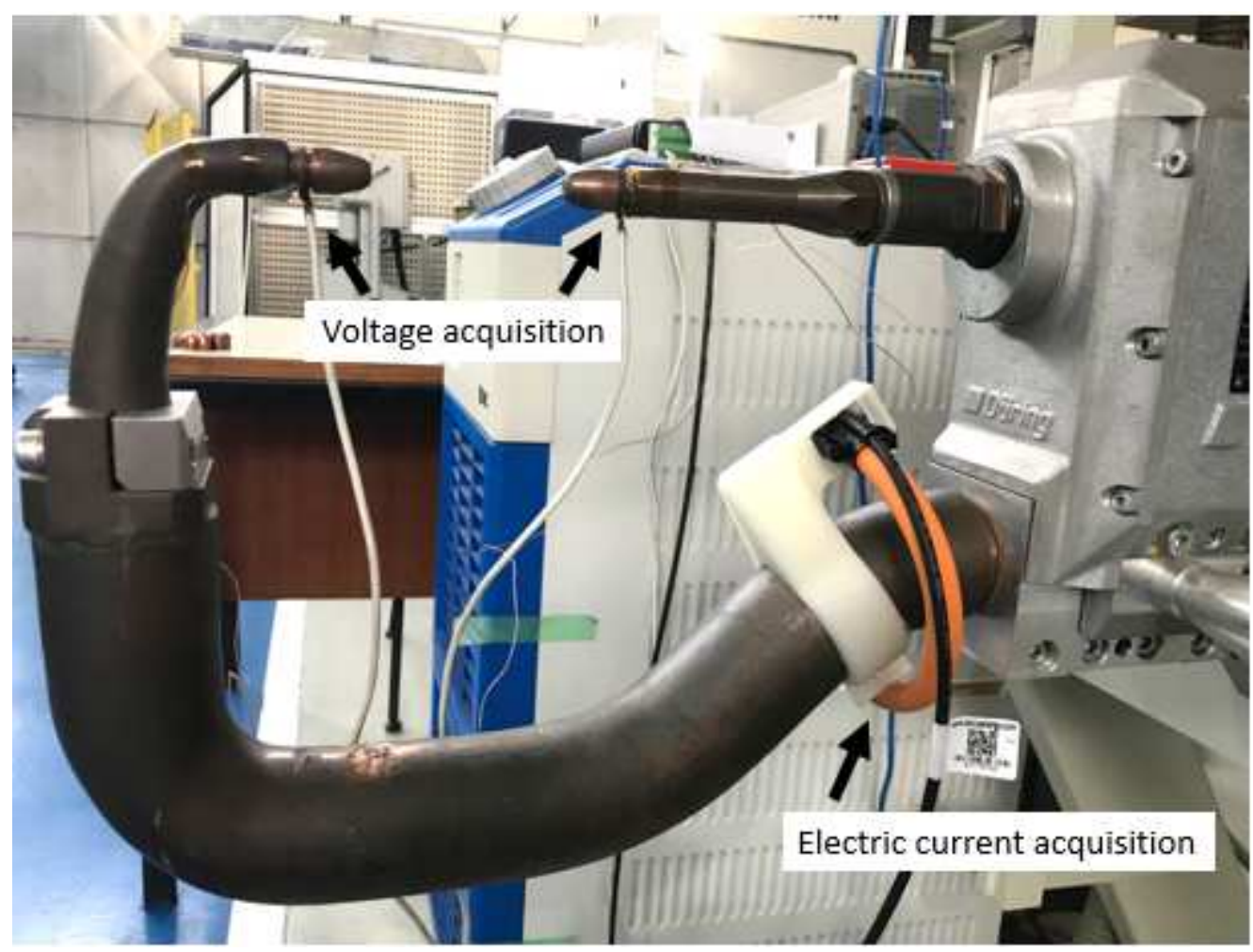

Figure 7

Clamp instrumentation to measure energy in the secondary transformers. 


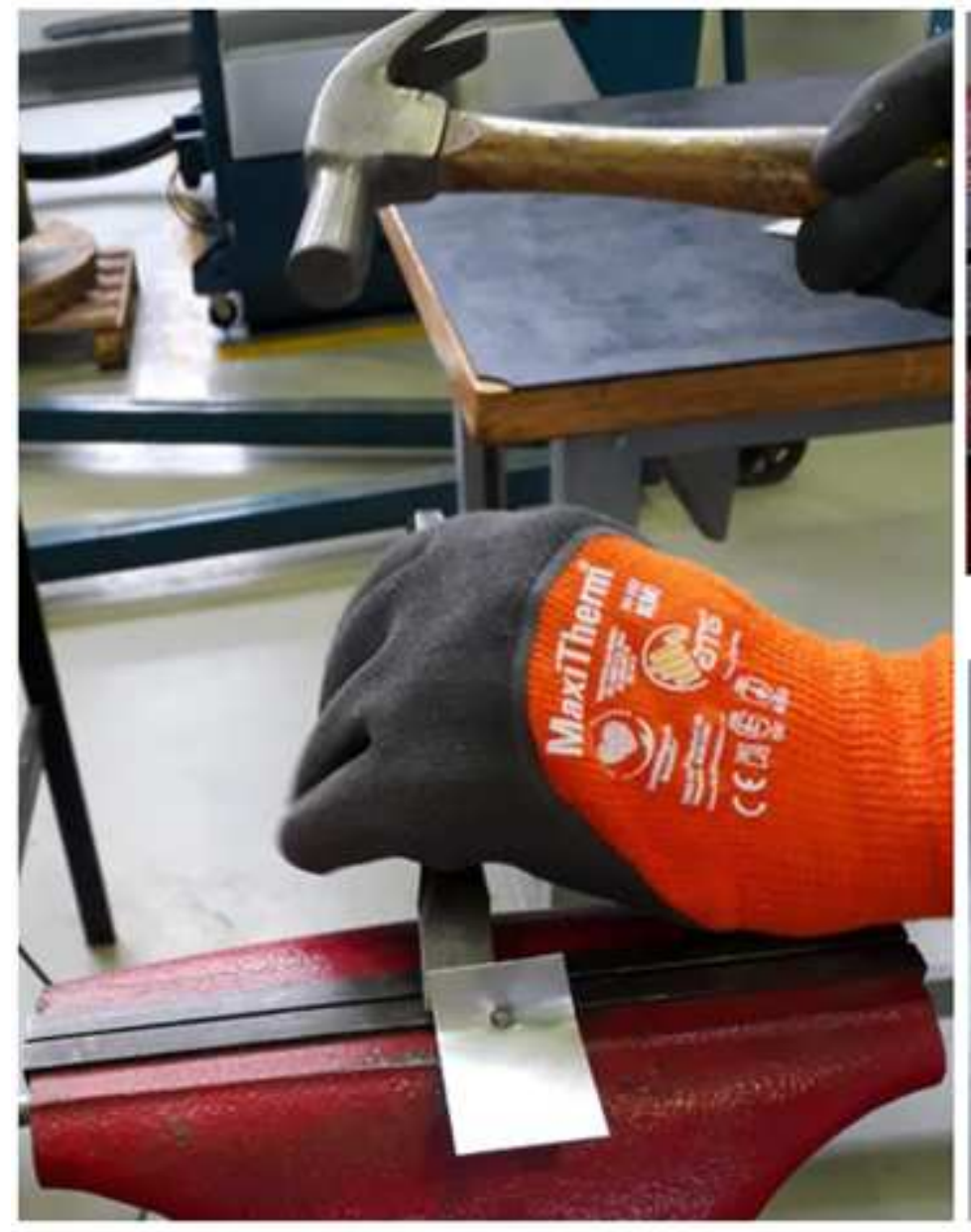

(a)

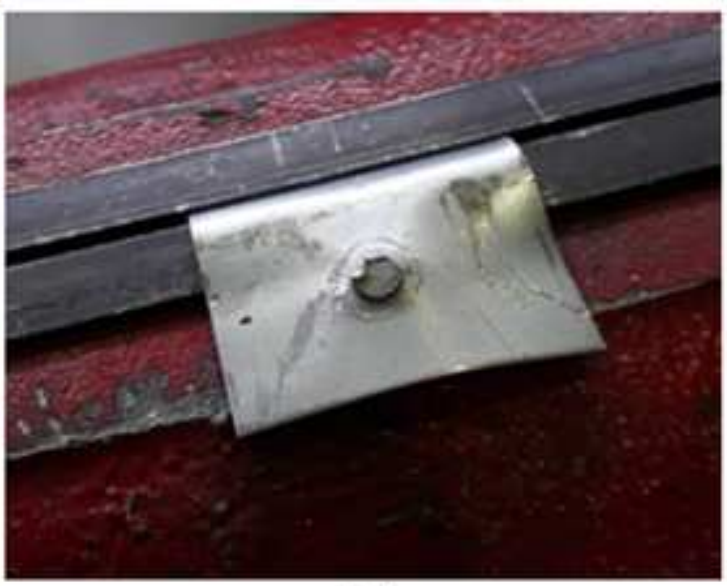

(b)

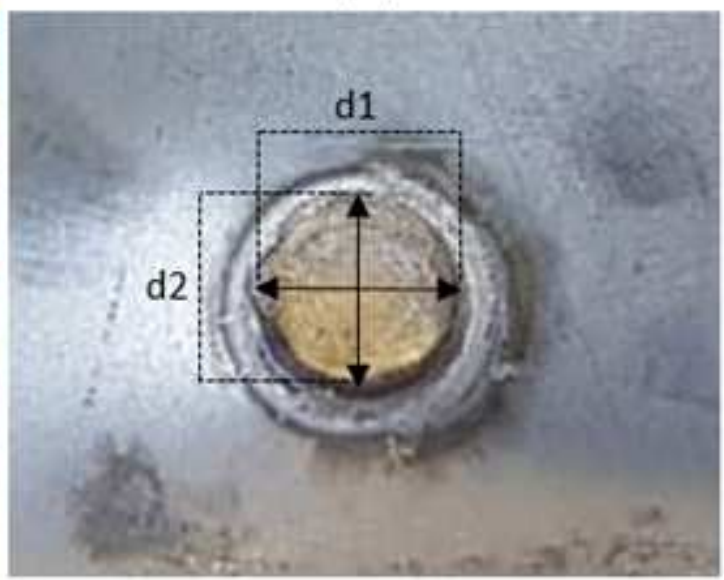

(c)

\section{Figure 8}

Peel test performing. In (a), steel sheets are separated. In (b), the detached nugget is presented. In (c), the measurement positions d_1 and d_2 are exemplified. 


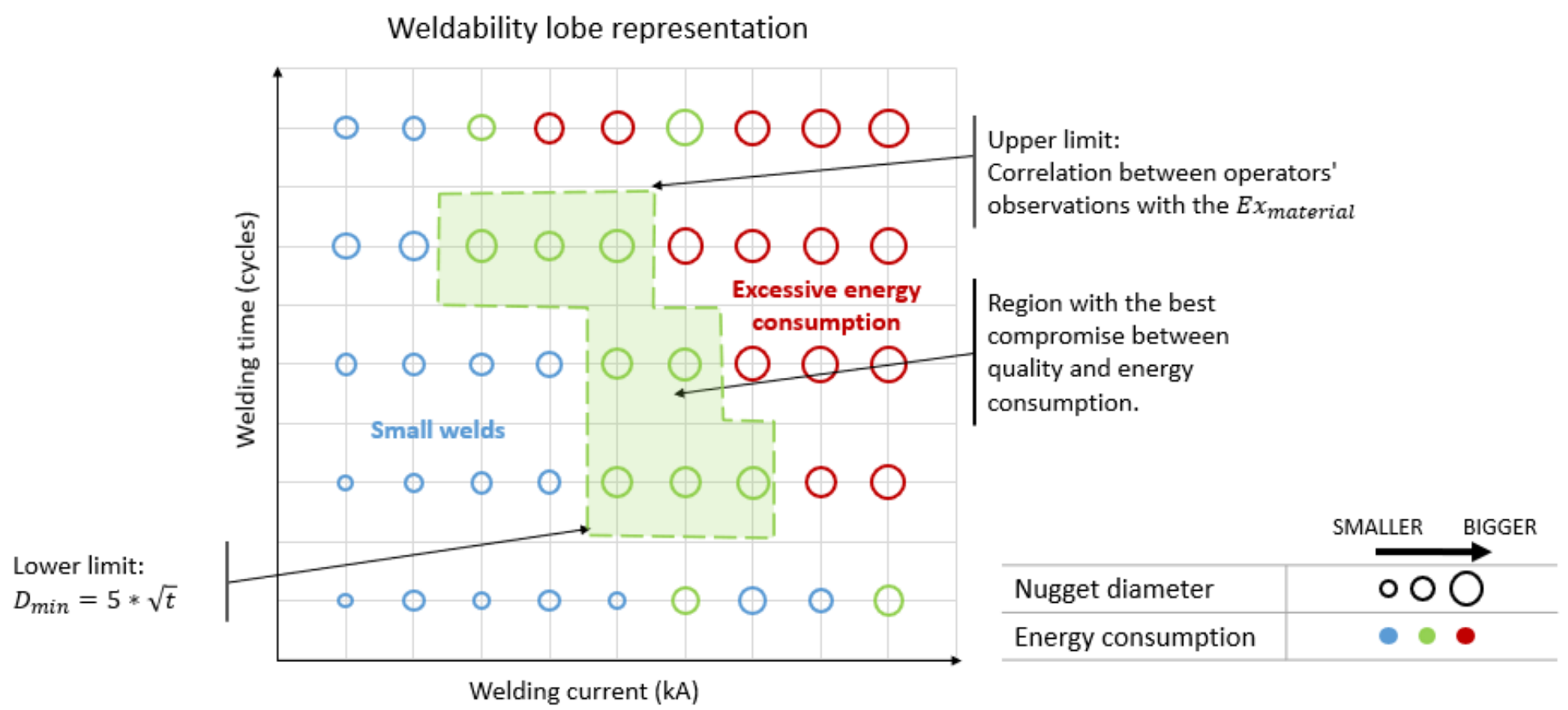

Figure 9

Weldability lobe representation highlighting the region with the best compromise between quality and energy consumption. 


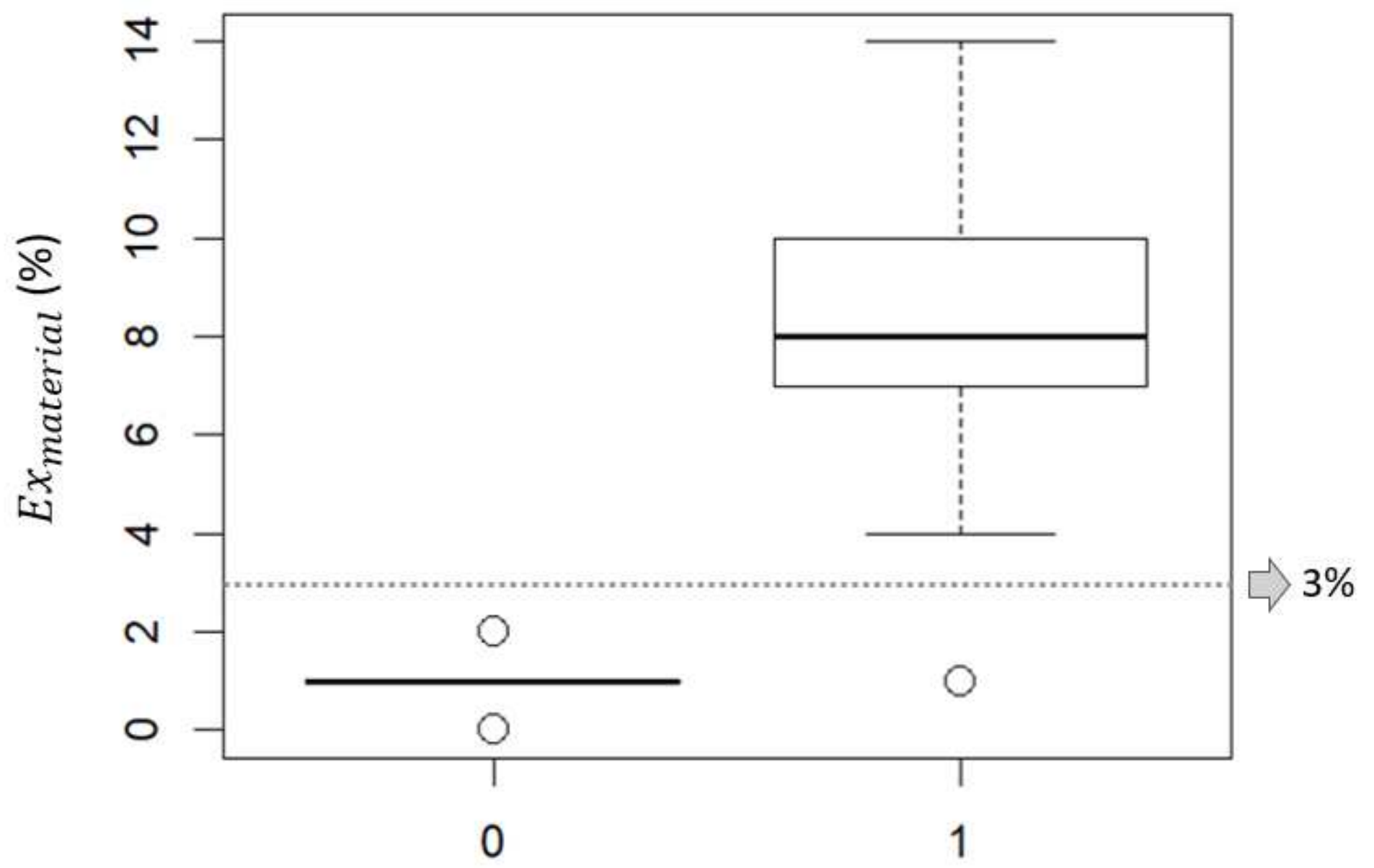

Operators' observations

Figure 10

Material expulsion indicator (\%) by observations of the operators during the samples' manufacture. " 0 " indicates that expulsion was not observed, and "1", the opposite. 

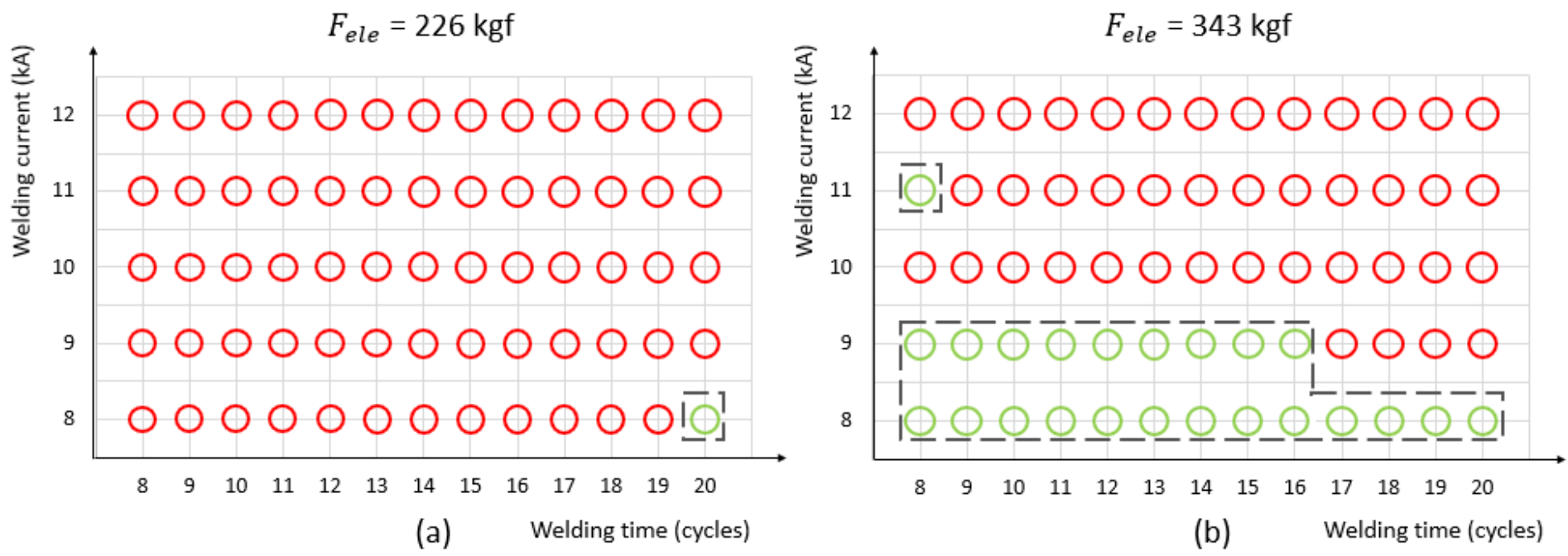

\begin{tabular}{l|c}
\hline Nugget diameter & $\begin{array}{c}\longrightarrow \\
\text { SMALLER } \\
\text { No expulsion }\end{array}$ \\
\hline Expulsion & $\bigcirc$ \\
\hline Weldability lobe & こニー」 \\
\hline
\end{tabular}

\section{Figure 11}

In (a), the diameter values are presented using F_ele $=226 \mathrm{kgf}$ and, in (b), F_ele $=343 \mathrm{kgf}$. The nuggets that had an expulsion indicator of less than $3 \%$ are presented in green. The weldability lobe is highlighted considering the nugget diameter greater than $4.53 \mathrm{~mm}$, and the material expulsion indicator less than $3 \%$. 


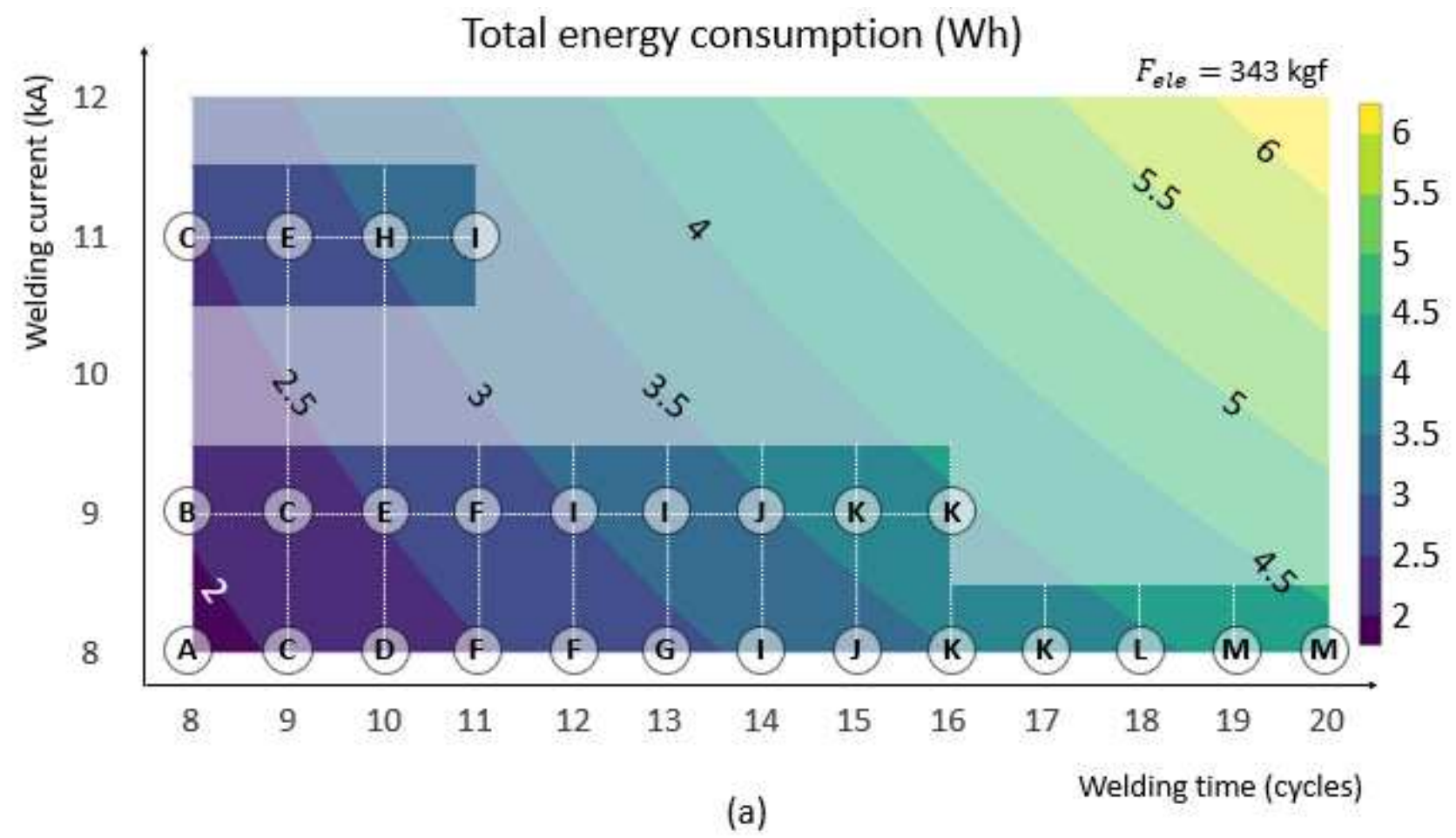

Total energy efficiency indicator $(\mathrm{mm} / \mathrm{Wh})$

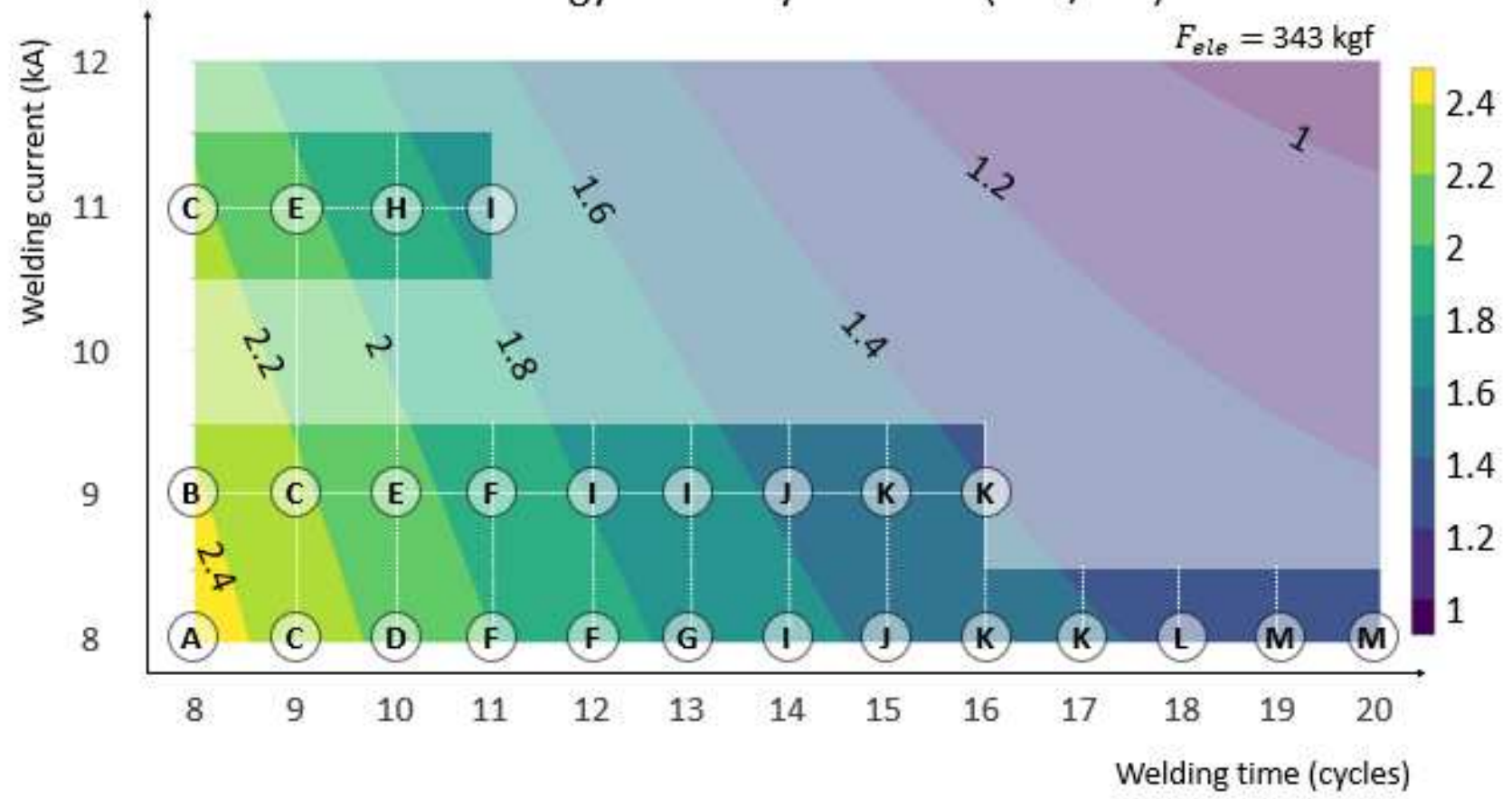

(b)

\section{Figure 12}

Contour lines of the predicted models for total energy consumption (a) and total energy efficiency indicator (b) applied in the weldability lobe for $F_{-}$ele $=343 \mathrm{kgf}$. The letters A to $\mathrm{M}$ represent energy labels where $A$ indicates the best energy performance and $M$, the worst. 


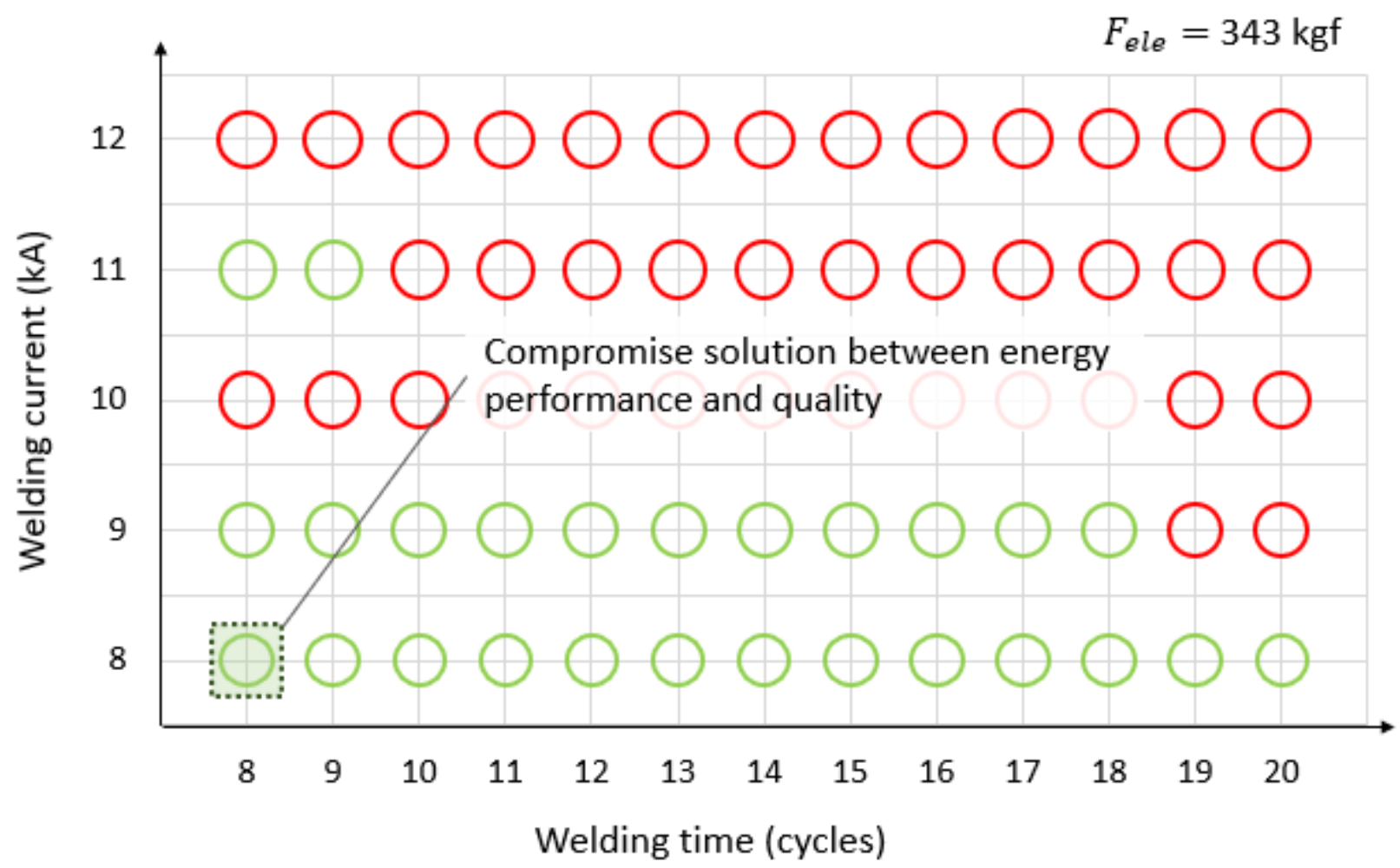

\begin{tabular}{|c|c|}
\hline Nugget diameter & $\underset{\text { SMALLER }}{\mathrm{O}} \longrightarrow \underset{\text { BIGGER }}{\mathrm{O}}$ \\
\hline No expulsion & 0 \\
\hline Expulsion & 0 \\
\hline Compromise solution & (1)............: \\
\hline
\end{tabular}

Figure 13

Compromise solution between total energy efficiency, energy consumption, and quality. 


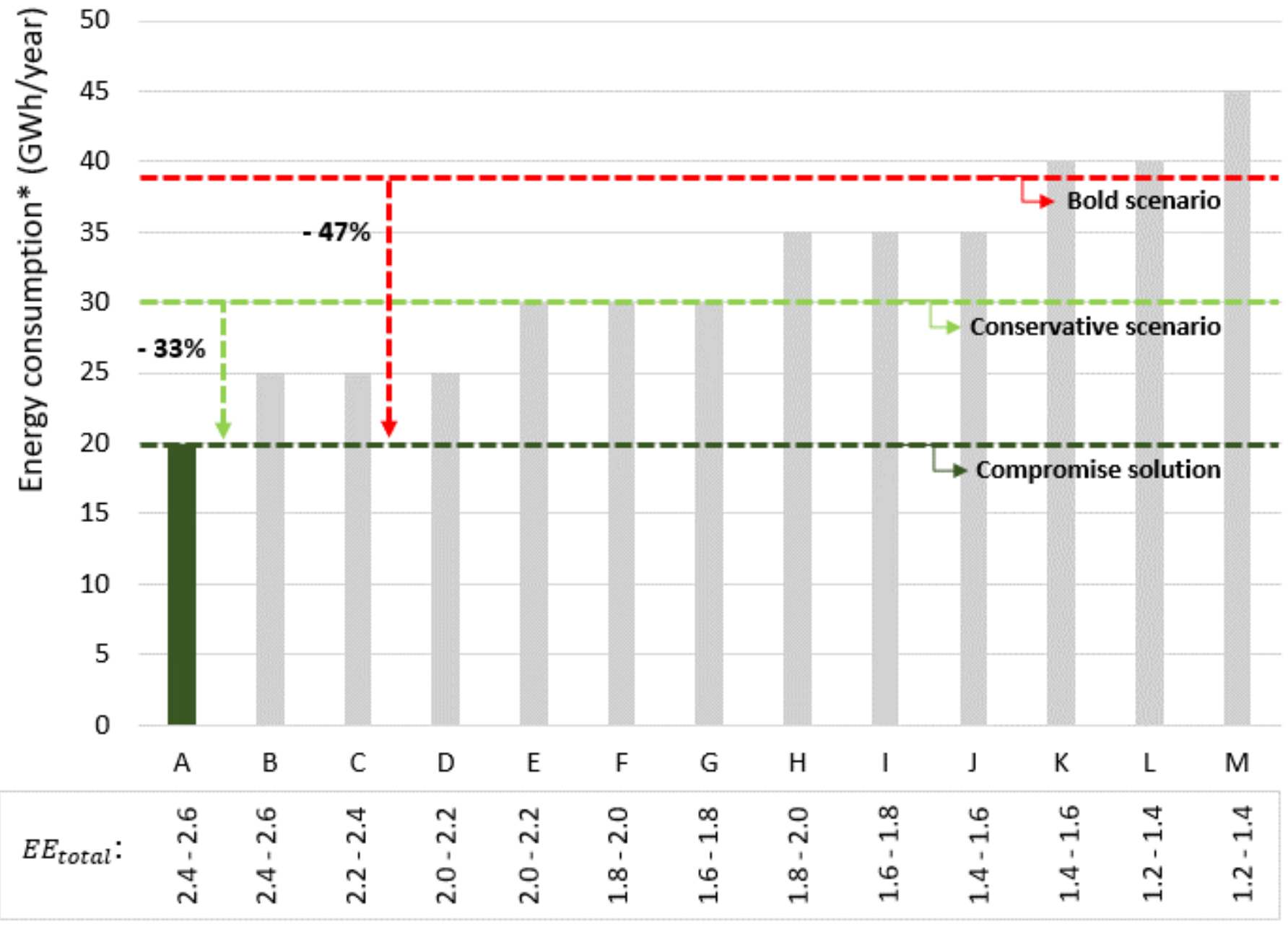

* Considering the production of 10 billion spot welds/year

Energy labels

Bold scenario: Energy consumption average of all samples that presented satisfactory quality for the industrial criterion ( $d_{\text {nugget }}>4.53 \mathrm{~mm}$ )

Conservative scenario: Energy consumption average of all samples inserted in the weldability lobe ( $d_{\text {nugget }}>4.53$ $\mathrm{mm}$ and $E x_{\text {material }}<3 \%$ )

Compromise solution: Energy consumption of the better cost-benefit ratio between energy consumption and quality $\left(d_{\text {nugget }}>4.53 \mathrm{~mm}, E x_{\text {material }}<3 \%\right.$ and $\left.E C_{\text {total }}=2 \mathrm{Wh}\right)$

\section{Figure 14}

Annual energy consumption considering the production of 10 billion spot welds per year for the proposed energy labels. The average energy consumption is highlighted for the bold (energy consumption average of all samples that presented satisfactory quality for the industrial criterion - d_nugget $>4.53 \mathrm{~mm}$ ) and conservative (energy consumption average of all samples inserted in the weldability lobe - d_nugget > $4.53 \mathrm{~mm}$ and Ex_material < 3\%) scenarios and for the compromise solution (d_nugget $>4.53 \mathrm{~mm}$ Ex_material $<3 \%$ and EC_total $=2 \mathrm{Wh}$ ). 


\section{Supplementary Files}

This is a list of supplementary files associated with this preprint. Click to download.

- Tables.docx 